\title{
Transition Metal Imido Complexes
}

\author{
Thomas R. Cundari' \\ Contribution from The Department of Chemistry, Memphis State University, Memphis, \\ Tennessee 38152. Received February 13, 1992
}

\begin{abstract}
A wide range of transition metal imido (TMI) complexes is studied using ab initio molecular orbital (MO) calculations. The main computational point of interest is the further testing of effective core potentials (ECPs) and valence basis sets to allow for the accurate calculation of properties for reasonably sized transition metal complexes. On the chemical side, several results from the study are to be noted. The agreement between geometries for calculated models and their experimental counterparts ranges from very good to excellent, as found in previous studies of multiply bonded transition metal-group IVA complexes. Taken together, these data suggest that the accuracy one has come to expect for the prediction of structural properties for main-group compounds may yet become a reality for transition metal complexes. The correct prediction of molecular structure also leads one to infer that the bonding in these complexes is also accurately described. The $\mathrm{MC} / \mathrm{LMO} / \mathrm{CI}$ (multiconfigurational/localized $\mathrm{MO} /$ configuration interaction) technique shows that eight resonance structures are most significant in the description of the metal-imido linkage. Three of these account for roughly two-thirds of the total contributions; two resonance structures, both possessing a dative $\sigma$ bond, correspond to novel bonding descriptions for TMI complexes. The dative character of the $\sigma$ bond has been largely unappreciated. The $\mathrm{MC} / \mathrm{LMO} / \mathrm{CI}$ results also indicate that the metal-imido bond is intermediate between a double and a triple bond. Nucleophilic resonance structures decrease as one goes to the right in the transition series while electrophilic ones show the reverse behavior, in agreement with observed reactivity.
\end{abstract}

\section{Introduction}

The coordination of unstable and transient species to transition metal complexes has been a successful technique for chemists interested in studying them and harnessing their reactivity to carry out synthetic and catalytic transformations. Perhaps the most studied examples are the isovalent series: carbene $\left(\mathrm{CR}_{2}\right)$, nitrene (NR), and oxene (O). ${ }^{2-4}$ Having two unsatisfied valencies, these moieties form double bonds to a transition metal when coordinated as a terminal ligand and react similarly (donation of $N R$ and $O$ lone pairs into vacant metal orbitals can be invoked to yield a triple bond description). ${ }^{5}$ For example, the nitrene analogues of the Wittig reaction 6 and oxygen atom transfer ${ }^{7}$ are known. Oxo $\left(\mathrm{L}_{n} \mathrm{M}=\mathrm{O}\right)$ and carbene $\left(\mathrm{L}_{n} \mathrm{M}=\mathrm{C}(\mathrm{R}) \mathrm{R}^{\prime}\right)$ complexes have received much attention due to their importance in catalysis, biochemistry, and advanced materials. ${ }^{8,9}$

Transition metal imido (TMI) complexes have been relatively ignored by theoreticians, despite being putative intermediates in important processes such as ammoxidation and nitrogen fixation. ${ }^{5}$ Nitrenes were first proposed by Tiemann in 1892 as intermediates in the Lossen rearrangement. ${ }^{10}$ It seems appropriate that as nitrenes and Werner's coordination theory approach their 100th birthday that a detailed study of transition metal imido complexes be undertaken.

(1) E-mail: cundarit@ memstvx 1.memst.edu

(2) The first carbene complex, $\mathrm{W}(\mathrm{CO})_{5}(=\mathrm{C}(\mathrm{OMe})(\mathrm{Ph})$, was reported by Fischer and Maasbol in 1964. A discussion of various aspects of the chemistry of the so-called Fischer-type carbene complexes can be found in ref $2 a$. Schrock reported the first high-valent, alkylidene complex in 1975: $\left(\mathrm{Me}_{3} \mathrm{CCH}_{2}\right){ }_{3} \mathrm{Ta}\left(-\mathrm{C}(\mathrm{H}) \mathrm{CMe}_{3}\right)^{26}$ (a) Transition Metal Carbene Complexes; Dötz, K. H., Ed. Verlag: Weinheim, 1983, p 73. (b) Schrock, R. R. Acc. Chem. Res. 1979, 12, 98 .

(3) (a) Nugent, W. A.; Haymore, B. L. Coord. Chem. Rev. 1980, 3I, 123. (b) Cenini, S.; LaMonica, G. Inorg. Chim. Acta 1976, 18, 279. (c) Dehnicke K.; Străhle, J. Angew. Chem., Int. Ed. Engl. 1981, 20, 413. (d) Additional reviews to the most recent imido literature, some of which are not referenced here, can be found in footnote 1 of ref 19.

(4) The most complete reviews of metal-oxo complexes are as follows: (a) Holm, R. H. Chem. Rev. 1987, 87, 1401. (b) Griffith, W. P. Coord. Chem. Rev. $1970,5,459$.

(5) Nugent, W. A.; Mayer, J. M. Metal-Ligand Multiple Bonds; Wiley: New York, 1989.

(6) Rocklage, S. M.; Schrock, R. R. J. Am. Chem. Soc. 1980, 102, 7808.

(7) Groves, J. T.; Takahashi, T. J. Am. Chem. Soc. 1983, I05, 2073.

(8) In addition to experimental and theoretical references in the above reviews, ${ }^{2-5}$ more theoretical references can be found in references 8 (carbene complexes) and 9 (oxo complexes). Cundari, T. R.; Gordon, M. S. J. Am. Chem. Soc. 1991, 113, 5231 .

(9) Cundari, T. R.; Drago, R. S. Inorg. Chem. 1990, 29, 2303.

(10) Tiemann, F. Ber. Disch. Chem. Ges. 1891, 24, 4162.
Several molecular orbital (MO) analyses of imido complexes have been reported, many as adjuncts to experiment. Nugent et al. ${ }^{11}$ use $\mathrm{X} \alpha$ calculations and NMR data to probe the changes in nucleophilicity/electrophilicity as a function of position in the transition series. They conclude that the imido $\mathrm{N}$ becomes increasingly electrophilic (less nucleophilic) as one proceeds downward and to the right in the transition series. Maatta et al. use extended Hückel calculations of V-imido dimers to help interpret ${ }^{51}$ V NMR and electronic spectral data. ${ }^{12}$ Rothwell et al. employ extended Hückel theory (EHT) to assess competition for metal $\mathrm{d} \pi \mathrm{AOs}$ between the amido and imido ligands in $\mathrm{Zr}$ (NH) $\left(\mathrm{NH}_{2}\right)_{2}\left(\mathrm{NH}_{3}\right)_{2}$, a model of their characterized complex. ${ }^{13}$ Trogler and co-workers ${ }^{14}$ combine density functional calculations, EPR, and X-ray crystal data to analyze the electronic structure of $\mathrm{Cp}_{2} \mathrm{VN}\left(2,6-\mathrm{Me}_{2}-\mathrm{Ph}\right)$. An extended Hückel analysis of the reaction of Os-oxo(imido) complexes with olefins has been published. ${ }^{15}$ Complexes pertinent to nitrogen fixation $\left(\mathrm{N}_{2}, \mathrm{NNH}\right.$, $\mathrm{NNH}_{2}$, etc.) were studied by Dubois and Hoffmann ${ }^{16}$ using EHT and Fukui et al. using $\mathrm{CNDO} / 2^{17}$ and minimal basis set ab initio calculations. ${ }^{18}$ Schrock et al. have published $\mathrm{X} \alpha$ calculations of $\mathrm{Os}(\mathrm{NH})_{3}$ and related $\mathrm{d}^{2}-\mathrm{Os}$ imidos in conjunction with experiment. ${ }^{19}$

Each TMI complex has a description of the metal-imido bond suggested by its observed reactivity. Early transition metal imido complexes are typically envisioned as containing a metal-imido triple (or double) bond and a nucleophilic imido nitrogen, $1\left(\sigma_{\mathrm{MN}}\right.$ $\left.+2 \pi_{\mathrm{MN}}\right)$ or $2\left(\sigma_{\mathrm{MN}}+\pi_{\mathrm{MN}}+1 \mathrm{p}_{\mathrm{N}}\right)$. A bonding scheme ostensibly identical to 2 , i.e., a triple bond with dative character for one $\pi$ component, 3, has also been forwarded. ${ }^{3 c}$ Late TMIs have electrophilic imido nitrogens with a metal-imido linkage which has been described in terms of a $\mathrm{MN} \sigma$ bond, a $N$ lone pair, and a filled metal $\mathrm{d} \pi$ orbital for back-bonding to the imido ligand, 4. ${ }^{20}$

(11) Nugent, W. A.; McKinney, R. J.; Kasowski, R. V.; Van-Catledge, F. A. Inorg. Chim. Acta 1982, 65, L91.

(12) Devore, D. D.; Lichtenhan, J. D.; Takusagawa, F.; Maatta, E. A. J. Am. Chem. Soc. 1987, 109, 7408 .

(13) Profilet, R. D.; Zambrano, C. H.; Fanwick, P. E.; Nash, J. J.; Rothwell, I. P. Inorg. Chem. 1990, 29, 4364.

(14) Osborne, J. H.; Rheingold, J. H.; Trogler, W. C. J. Am. Chem. Soc. $1985,107,7945$.

(15) Jorgensen, K. A.; Hoffmann, R. J. Am. Chem. Soc. 1986, 108, 1867.

(16) Hoffmann, R.; Dubois, D. L. Nouv. J. Chim. 1977, $1,479$.

(17) Yamabe, T.; Hori, K.; Minato, T.; Fukui, K. Inorg. Chem. 1980, 19, 2154.

(18) Yamabe, T.; Hori, K.; Fukui, K. Inorg. Chem. 1982, 21, 2046, 2816.

(19) Schofield, M. H.; Kee, T. P.; Anhaus, J. T.; Schrock, R. R.; Johnson, K. H.; Davis, W. M. Inorg. Chem. 1991, 30, 3595. 


$$
\mathrm{L}_{\mathrm{n}} \mathrm{M} \equiv \mathrm{NR} \quad \mathrm{L}_{\mathrm{n}} \mathrm{M}=\overline{\mathrm{N}} \mathrm{R} \quad \mathrm{L}_{\mathrm{n}} \mathrm{M} \leftrightarrows \mathrm{NR} \quad \mathrm{L}_{\mathrm{n}} \mathrm{M} \stackrel{\mathrm{NR}}{ }
$$

2

One can envision a description of the metal-imido bond in terms of three MOs, although this need not imply that it is analogous to the $\mathrm{CC}$ bond of acetylene. Of the maximum of three bonds which can join the metal and nitrogen, one is $\sigma$-like while the other two are $\pi$-like. For the two $\pi$ components to be symmetry equivalent the $\mathrm{M}-\mathrm{N}-\mathrm{R}$ angle must be $180^{\circ}$ and there must be a 3-fold or greater rotation axis about $\mathrm{M}-\mathrm{N}-\mathrm{R}$. The $\pi$ components perpendicular and parallel to the $\mathrm{M}-\mathrm{N}-\mathrm{R}$ plane are referred to as $\pi_{\perp}$ and $\pi_{\|}(5)$, respectively. The metal-imido bond of the TMI complex $\left(\mathrm{L}_{n} \mathrm{M}(\mathrm{NR})\right)$ can be described by wave functions such as in eq 1 , in which the MOs are localized with no contributions from ligands $\left(\mathrm{L}_{n}\right)$ or substituents $(\mathrm{R})$. The mixing parameters

$$
\begin{gathered}
\sigma_{\mathrm{MN}} \approx\left(\sigma_{\mathrm{N}}+\lambda * \sigma_{\mathrm{M}}\right) \\
\pi_{\mathrm{MN}}(\|) \approx\left(\pi_{\mathrm{N}}(\|)+\lambda^{\prime *} \pi_{\mathrm{M}}(\|)\right) \\
\pi_{\mathrm{MN}}(\perp) \approx\left(\pi_{\mathrm{N}}(\perp)+\lambda^{\prime \prime *} \pi_{\mathrm{M}}(\perp)\right)
\end{gathered}
$$

$\left(\lambda, \lambda^{\prime}\right.$, and $\left.\lambda^{\prime \prime}\right)$ measure the polarization of the MO in question. For example, $\lambda=1$ in eq la signifies a covalent $\sigma$ bond, $\lambda^{\prime}=0$ constitutes a dative ligand-to-metal $\pi$ interaction, and $\lambda^{\prime \prime}=\infty$ indicates a metal-to-ligand $\pi$ back-bond. Each Lewis structure can be fit into this scheme by adjustment of the mixing parameters. For example, Basolo has formulated nitrene complexes (electrophilic N) in terms of Lewis structure 4, while an imide complex (nucleophilic $\mathbf{N}$ ) is given the Lewis structure description in $6 .{ }^{20}$ The three-orbital picture above has $\lambda=1 ; \lambda^{\prime}=0 ; \lambda^{\prime \prime}=\infty$ for 4 and $\lambda=1 ; \lambda^{\prime}=\lambda^{\prime \prime}=0$ for 6 .

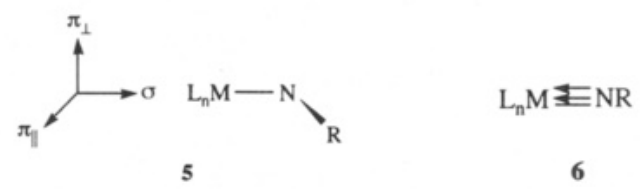

The various bonding descriptions used to describe imido complexes are reminiscent of those employed to rationalize the chemical reactivity of alkylidene complexes. ${ }^{8,21,22}$ The similarity is not unexpected and suggests that work on alkylidenes ${ }^{8,21,22}$ may be extended to imidos. Indeed, imido complexes were chosen for this and several other reasons. First, the paucity of detailed computational treatments is surprising given the experimental interest in imido complexes. ${ }^{3,5}$ Second, imidos are a logical extension of previous studies of multiple bonding between transition metals and group IVA elements (C, Si, Ge, and $\mathrm{Sn}){ }^{8,21,22}$ Third, TMI complexes have been isolated or proposed for nearly the entire transition series (excluding only the $\mathrm{Zn}$ triad) and provide an ideal test for methods capable of handling the transition metals, as part of a program to expand $a b$ initio methods to the entire periodic table.

This paper is organized in two sections. First, TMI geometries are presented and compared to existing experimental data. Second, the bonding in various imido complexes is discussed. Bonding is analyzed with the $\mathrm{MC} / \mathrm{LMO} / \mathrm{CI}$ (multiconfigurational/ localized molecular orbital/configuration interaction) scheme previously used for metal-group IVA multiply bonded complexes. ${ }^{8,21,22}$

\section{Computational Methods}

The calculations described herein are done with the ab initio program GAMESS. ${ }^{23}$ Effective core potentials (ECPs) replace the chemically

(20) Basolo, F. J. Indian Chem. Soc. 1977, 54, 7.

(21) Cundari, T. R.; Gordon, M. S. Organometallics 1992, 11, 55.

(22) (a) Cundari, T. R.; Gordon, M. S. J. Am. Chem. Soc. 1992, 114, 539.

(b) Cundari, T. R.; Gordon, M. S. J. Phys. Chem. 1992, 96, 631. (c) Cundari, T. R.; Gordon, M. S. Organometallics, in press.

(23) GAMESS (General Atomic and Molecular Electronic Structure System): Schmidt, M. W.; Baldridge, K. K.; Boatz, J. A.; Jensen, J. H.; Koseki, S.; Gordon, M. S.; Nguyen, K. A.; Windus, T. L.; Elbert, S. T. QCPE Bull. 1990, 10, 52 .

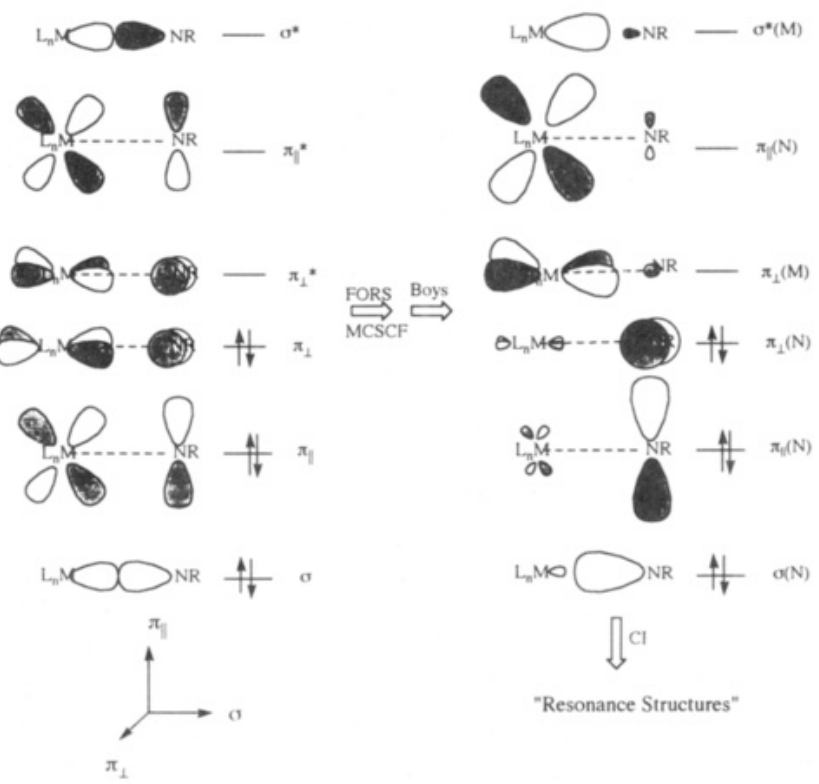

Figure 1. Schematic representation of important molecular orbitals in transition metal imido (TMI) complexes, i.e., those which describe the metal-nitrogen bond, and their conversion from canonical RHF MOs to "resonance structures" by means of the MC/LMO/CI method.

less important core orbitals and thus make calculations feasible for all rows of the transition series. The ECPs and valence basis sets of Stevens, Basch, Krauss, and Jasien (SBKJ) ${ }^{24}$ are used for heavy atoms while $\mathrm{H}$ atoms are described with the $-31 \mathrm{G}$ basis set. Basis sets for heavy main-group elements are augmented with a d polarization function. ${ }^{25}$ Geometry optimizations employ the method of Baker ${ }^{26}$ and unless stated otherwise are done at the restricted Hartree-Fock (RHF) level for closed-shell singlets. The energy hessian (second derivative of the energy as a function of nuclear coordinates) is calculated at stationary points in order to identify them as minima (all positive vibrational frequencies), transition states (one negative vibrational frequency), or higher order stationary points. Intrinsic vibrational frequencies (and force constants) are obtained by the method of Boatz and Gordon. ${ }^{27}$

Some geometry optimization and single point calculations are done at the MCSCF (multiconfiguration self consistent field) level of theory ${ }^{28}$ to assess the importance of electron correlation in describing the metal-imido bond. As discussed above, six electrons are located in the $\mathrm{MN}$ bonding region for TMI complexes, regardless of which Lewis structure in 1-4 or $\mathbf{6}$ (or any other reasonable structure) is chosen. In most cases, some covalent character exists in all metal-imido MOs so that a bonding scheme like that in Figure 1 is appropriate. The six metal-imido electrons are used to construct the six-orbital/six-electron (6/6) MCSCF active space. The FORS-MCSCF (full optimized reaction space) method generates all electronic configurations (configuration state functions, CSFs) of a given multiplicity by distributing the six electrons among the six MOs in all possible ways; there are 175 CSFs for the $(6 / 6)$ case when no symmetry restrictions exist. The contribution each CSF makes to the total wave function is optimized as are the MOs in each CSF.

The procedure used to analyze the electronic structures of TMI complexes is the MC/LMO/CI method previously used for alkylidene complexes and main group compounds. ${ }^{8,22} \mathrm{MC} / \mathrm{LMO} / \mathrm{CI}$ has been described in detail elsewhere, only the highlights are repeated here. ${ }^{8,28 \mathrm{~b}}$ The MC/LMO/CI method is a three step process, Figure 1.

(i) The bonding and antibonding MOs which correspond to the bond of interest are located, and a FORS-MCSCF single point calculation is carried out at the RHF minimum. Since the metal-imido linkage is formally a triple bond, the active space is a (6/6) FORS-MCSCF. The MCSCF step has two main advantages: it improves the description of

(24) Krauss, M.; Stevens, W. J.; Basch, H.; Jasien, P. G. Can. J. Chem. 1992, 70, 612

(25) Pople, J. A.; Hehre, W. J.; Radom, L.; Schleyer, P. v. R. Ab-Initio Molecular Orbital Theory; Wiley: New York, 1986, Section 4.3.

(26) Baker, J. J. Comput. Chem. 1986, 7, 385.

(27) Boatz, J. A.; Gordon, M. S. J. Phys. Chem. 1989, 93, 1819.

(28) (a) Ruedenberg, K.; Schmidt, M. W.; Dombek, M. M.; Elbert, S. T. Chem. Phys. 1982, 71, 41, 51, 65. (b) For a detailed theoretical description of the MC/LMO/CI technique and its application to main-group compounds, see: Lam, B.; Schmidt, M. W.; Ruedenberg, K. J. Phys. Chem. 1985, 89, 2221.

(29) Foster, J. M.; Boys, S. F. Rev. Mod. Phys. 1960, 32, 300. 
Table I. Geometries of Sc Triad Imido Complexes ${ }^{a}$

\begin{tabular}{lcccccc}
\hline $\begin{array}{c}\mathrm{M}=\mathrm{Sc}, \\
\mathrm{X}=\mathrm{Cp}\end{array}$ & $\mathbf{M}=\mathrm{Sc}^{+}$ & $\begin{array}{c}\mathrm{M}=\mathrm{Y}, \\
\mathrm{X}=\mathrm{Cp}\end{array}$ & $\mathbf{M}=\mathrm{Y}^{+}$ & $\begin{array}{c}\mathrm{M}=\mathrm{La}, \\
\mathrm{X}=\mathrm{Cp}\end{array}$ & $\mathbf{M}=\mathrm{La}^{+}$ \\
\hline $\mathrm{M}-\mathrm{N}$ & 1.78 & 1.70 & 1.93 & 1.84 & 2.07 & 1.97 \\
$\nu_{\mathrm{MN}^{b}}$ & 982 & 1111 & 854 & 977 & 760 & 869 \\
${\mathrm{M}-\mathrm{Ct}^{\mathrm{r}}}$ & 2.26 & & 2.51 & & 2.79 & \\
\hline
\end{tabular}

${ }^{a}$ Geometries (bond lengths in $\AA$ ) are calculated at the RHF level for $\mathrm{CpMNH}$ and $\mathrm{MNH}^{+}$complexes, $\mathrm{M}=\mathrm{Sc}, \mathrm{Y}$, and $\mathrm{La}$. The basis sets and techniques are those described in Computational Methods. ${ }^{b}$ The intrinsic stretching frequencies $\left(\nu_{\mathrm{MN}}\right)$, in $\mathrm{cm}^{-1}$, were calculated as described in ref 27. ${ }^{c} \mathrm{Ct}$ is the centroid of the $\eta^{5}-\mathrm{Cp}$ ring.

the antibonding MOs which are unoccupied in the RHF wave function, and it localizes the active space MOs in the bonding region.

(ii) Since the MCSCF wave function is of the FORS type (i.e., all possible combinations of six electrons in six orbitals are included) one can Boys $^{29}$ localize the active space MOs to yield "AO-like" MOs. The "AO-like" MOs are highly polarized, are located on either end of the MN bond, and resemble nitrogen and metal AOs or hybrid orbitals, Figure 1. A Mulliken population analysis reveals that the "AO-like" MOs are typically located $\geq 98 \%$ on either the $\mathrm{M}$ or $\mathrm{N}$ end of the metal-imido bond. It is the small tails on the other end of the bond $(\leq 2 \%)$ which maintain the orthogonality of the "AO-like" MOs. These tails distinguish the $\mathrm{MC} / \mathrm{LMO} / \mathrm{CI}$ technique from a true valence bond calculation, but make MC/LMO/CI more computationally tractable.

(iii) Configuration interaction (CI) with a reference determinant of "AO-like" MOs is carried out to determine the weight of each resonance structure. The resonance structure with all six electrons in $\mathrm{N}$-based "AO-like" MOs, 7, is used as the reference determinant. Since the CI, like the FORS-MCSCF, includes all possible combinations, any reference determinant yields the same description of the bond in terms of a linear combination of resonance structures.

\section{$\mathrm{L}_{\mathrm{n}} \mathrm{M} \equiv \mathrm{NR}$}

7

\section{Results and Discussion}

1. Geometries. a. The Sc Triad. The Sc triad TMI complexes studied are $[\mathrm{MNH}]^{+}$and $\mathrm{CpMNH}$. The $\mathrm{Cp}\left(\mathrm{Cp}=\eta^{5}-\mathrm{C}_{5} \mathrm{H}_{5}\right)$ complexes, 8 , are chosen because of high symmetry $\left(C_{5 v}\right)$, preference of Sc triad metals for the +3 oxidation state $(\mathrm{NH}$ is formally -2 ), and structural similarity to $\operatorname{Ir}\left(\right.$ III) imidos. ${ }^{30}$ The

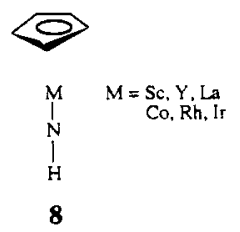

group IIIB imido cations have been generated in the gas phase. ${ }^{31}$ $\mathrm{MNH}^{+}$has $C_{\infty}$ symmetry. Pertinent geometric data is shown in Table I. In all cases, $\mathrm{N}-\mathrm{H}=1.02 \pm 0.01 \AA$ and $\mathrm{M}-\mathrm{N}-\mathrm{H}=$ $180^{\circ}$, and these are not listed in Table I. A linear coordination geometry is typically taken to indicate a metal-imido triple bond formulation. Most characterized early TMI complexes have linear or near linear $\left(>160^{\circ}\right) \mathrm{M}-\mathrm{N}-\mathrm{R}$ angles. ${ }^{32}$ For the $\mathrm{Cp}$ ligand, $\mathrm{C}-\mathrm{C}$ and $\mathrm{C}-\mathrm{H}$ bond lengths are typical, $\approx 1.43 \AA$ and $1.09 \AA$, respectively. Of the CpMNH complexes, only $\mathrm{CpScNH}$ is a minimum; the $\mathrm{La}$ and $\mathrm{Y}$ analogues possess a doubly degenerate imaginary mode ( $37 i$ for $Y$ and $60 i$ for $\mathrm{La}$ ) corresponding to a motion such that the centroid of the $C p$ ring is no longer collinear with $\mathrm{M}, \mathrm{N}$, and $\mathrm{H}^{33}$

(30) (a) Glueck, D. S.; Hollander, F. J.; Bergman, R. G. J. Am. Chem. Soc. 1989, 111,2719 . (b) Glueck, D. S.; Wu, J.; Hollander, F. J.; Bergman, R. G. J. Am. Chem. Soc. 1991, I13, 2041.

(31) Buckner, S. W.; Gord, J. R.; Frieser, B. S. J. Am. Chem. Soc. 1988, 110,6606 .

(32) See metrical data in ref 5 , pp 179-186.

(33) Given the large size of $\mathrm{Cp}$, smaller models are also calculated in which $\mathrm{Cp}_{\mathrm{p}}$ is replaced with $\mathrm{H}$ or $\mathrm{Cl}$ to test the assumption that they are suitable models for $\mathrm{Cp}_{\mathrm{p}}$ which was found to be true in alkylidene studies. ${ }^{8,22 a}$ Similar molecular and electronic structure is found for $X \cdot M(N H), X=C p, C l$, or $\mathrm{H} ; \mathrm{M}=\mathrm{Sc}, \mathrm{Y}$, or La
Table II. Geometries of Ti Triad Imido Complexes, $\mathrm{X}_{2} \mathrm{M}=\mathrm{NR}^{\circ}$

\begin{tabular}{llll}
\hline & \multicolumn{1}{c}{$\mathrm{Ti}$} & \multicolumn{1}{c}{$\mathrm{Zr}$} & \multicolumn{1}{c}{$\mathrm{Hf}$} \\
\hline $\mathrm{X}=\mathrm{H}, \mathrm{R}=\mathrm{H}$ & & & \\
$\mathrm{M}-\mathrm{N}$ & 1.65 & $1.81(1.80)$ & $1.80(1.79)$ \\
$\mathrm{N}-\mathrm{R}$ & 1.01 & $1.01(1.01)$ & $1.01(1.01)$ \\
$\mathrm{M}-\mathrm{N}-\mathrm{R}$ & 180 & $180(175)$ & $180(175)$ \\
$\nu_{\mathrm{MN}}{ }^{2}$ & 1139 & $1012(1016)$ & $1014(1016)$ \\
$\mathrm{X}=\mathrm{H}, \mathrm{R}=\mathrm{Cl}$ & & & \\
$\mathrm{M}-\mathrm{N}$ & 1.65 & $1.82(1.81)$ & $1.80(1.80)$ \\
$\mathrm{N}-\mathrm{R}$ & 1.65 & $1.66(1.66)$ & $1.66(1.66)$ \\
$\mathrm{M}-\mathrm{N}-\mathrm{R}$ & 180 & $180(175)$ & $180(170)$ \\
$\nu_{\mathrm{MN}}$ & 1087 & $968(974)$ & $976(978)$ \\
$\mathrm{X}=\mathrm{Cl}, \mathrm{R}=\mathrm{H}$ & & & \\
$\mathrm{M}-\mathrm{N}$ & 1.64 & 1.79 & 1.78 \\
$\mathrm{~N}-\mathrm{R}$ & 1.01 & 1.01 & 1.01 \\
$\mathrm{M}-\mathrm{N}-\mathrm{R}$ & 180 & 180 & 180 \\
$\nu_{\mathrm{MN}}$ & 1155 & 1034 & 1039 \\
$\mathrm{X}=\mathrm{Cl}, \mathrm{R}=\mathrm{Cl}$ & & & \\
$\mathrm{M}-\mathrm{N}$ & 1.65 & 1.80 & 1.79 \\
$\mathrm{~N}-\mathrm{R}$ & 1.65 & 1.60 & 1.66 \\
$\mathrm{M}-\mathrm{N}-\mathrm{R}$ & 180 & 180 & 180 \\
$\nu_{\mathrm{MN}}$ & 1088 & 988 & 998 \\
\hline
\end{tabular}

${ }^{a}$ The values calculated in Table II were done so with an RHF wave function and the basis sets and methods described in the text. The values in parentheses correspond to geometries for the lower symmetry minima when the $C_{2 v}$ stationary point (values not in parentheses) possesses an imaginary frequency. For the imido complexes the imaginary frequency corresponds to pyramidalization about the metal atom, 10 (Bond lengths in $\AA$; bond angles in deg.) ${ }^{b}$ Quoted intrinsic stretching frequencies $\left(\nu_{\mathrm{MN}}\right)$, are reported in $\mathrm{cm}^{-1}$.

Given the small size of $\mathrm{MNH}^{+}$, geometry optimizations at the MCSCF level are feasible. Calculated $\mathbf{M}-\mathbf{N}$ bond lengths for these $C_{\infty \infty}$ species are $1.75 \AA(\mathrm{Sc}), 1.88 \AA(\mathrm{Y})$, and $2.02 \AA(\mathrm{La})$, roughly $0.04-0.05 \AA(2-3 \%)$ longer at the MCSCF level vs RHF. Harrison and Kunze, using an all-electron basis and a similar electron correlation scheme, calculate a $\mathrm{ScN}$ bond length of 1.756 $\AA$ for $\mathrm{ScNH}^{+}$, in excellent agreement with that calculated here. ${ }^{32 \mathrm{~b}}$ The close agreement between ECP and traditional all-electron methods is typical ${ }^{8}$ and highlights the utility of the former for transition metal species, particularly the second and third series.

b. The Ti Triad. Group IVB imido models possess a maximum symmetry of $C_{2 v}, 9, \mathrm{X}_{2} \mathrm{M}(\mathrm{NR})$. Ligands $(\mathrm{X})$ and substituents

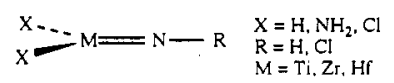

(R) are $\mathrm{H}$ and $\mathrm{Cl}$, Table II. The geometries of the $\mathrm{MX}$ fragment are virtually identical to those for carbene $\left(\mathrm{X}_{2} \mathbf{M}=\mathrm{CR}_{2}\right)$ analogues ${ }^{8,21,22 a}$ and are not listed in Table II. Table II highlights a problem of using $\mathrm{H}$ as a model for more demanding ligands, i.e., the appearance of "extra" imaginary frequencies due to bending of the $\mathrm{MH}_{n}$ fragment. In $\mathrm{H}_{2} \mathrm{M}(\mathrm{NR})(\mathrm{M}=\mathrm{Zr}$ or $\mathrm{Hf})$ there is an imaginary frequency corresponding to a change in the metal coordination environment from trigonal planar to pyramidal, 10. The changes brought about by the distortion are small: the pyramidal minima $\left(C_{s}\right)$ are $<1 \mathrm{kcal} / \mathrm{mol}$ below the $C_{2,}$ transition state, the $\mathrm{MN}$ bond does not change significantly $(\leq 0.01 \AA)$, and the $\mathrm{M}-\mathrm{N}-\mathrm{R}$ angle remains close to linear. The $\mathrm{Cl}_{2} \mathrm{M}(\mathrm{NR})$ complexes are minima at $C_{2 v}$ geometries.<smiles>[2H]N=NC=O</smiles>

(34) (a) Mavridis, A.; Kunze, K.; Harrison, J. F. In Bonding Energetics in Organometallics Compounds; Marks, T. J., Ed.; ACS Symposium Series 428, ACS: Washington, DC, 1990; p 263. (b) Harrison, J. F. Personal communication. Harrison and Kunze have also studied the imido complex HSc(NH) (Harrison, J. F.; Kunze, K. L. J. Am. Chem. Soc. 1990, 112, 3812) at the correlated level, using an all-electron basis set, and obtained $\mathrm{Sc}-\mathrm{N}=$ $1.809 \AA, \mathrm{Sc}-\mathrm{H}=2.018 \AA$, and $\mathrm{N}-\mathrm{H}=1.027 \AA$ for the linear complex. Using a (6/6) FORS-MCSCF wave function to correlate the Sc-N bond we obtain $\mathrm{Sc}-\mathrm{N}=1.82 \AA, \mathrm{Sc}-\mathrm{H}=1.99 \AA$, and $\mathrm{N}-\mathrm{H}=1.01 \AA$. We wish to thank Professor Harrison for pointing out that the values for the $\mathrm{Sc}-\mathrm{N}$ and $\mathrm{Sc}-\mathrm{H}$ bond lengths are reversed for $\mathrm{HSc}(\mathrm{NH})$ in ref $34 \mathrm{~b}$. 
Calculated $\mathbf{M}-\mathbf{N}$ bond lengths compare very well with experimentally characterized terminal imido complexes, despite increased steric bulk and coordinated neutral donor ligands for the latter. Calculated $\mathrm{Ti}-\mathrm{N}$ and $\mathrm{Zr}-\mathrm{N}$ bond lengths are in the range 1.64-1.65 $\AA$ and $1.79-1.83 \AA$ for imido complexes, respectively, Table II. The HfN bond lengths are from 0.01 to 0.02 $\AA$ less than $\mathrm{Zr}$ analogues in keeping with a slightly smaller covalent radius ( 1.44 vs $1.45 \AA$ ) for $\mathrm{Hf}$. Rothwell et al. ${ }^{35}$ measure a $\mathrm{Ti}-\mathrm{N}$ bond length of 1.719 (3) $\AA$ for $(\mathrm{OR})_{2}\left(\mathrm{py}^{\prime}\right)_{2} \mathrm{Ti}(\mathrm{NPh})$ while Roesky et al. obtain values of $1.720(2)^{36 \mathrm{a}}$ and $1.723(2) \AA^{36 \mathrm{~b}}$ for $\mathrm{Cl}_{2}$ (py) ${ }_{3} \mathrm{Ti}\left(\mathrm{NP}(\mathrm{S}) \mathrm{R}_{2}\right)(\mathrm{R}=i-\mathrm{Pr}$ or $\mathrm{Ph})$. In the least sterically hindered Ti-imidos, Ti-N bond lengths are notably shorter: 1.699 (4) $\AA$ for $\left[\mathrm{Ti}(\mathrm{TMEDA})(\mathrm{Cl})_{2}(\mathrm{~N}(\mathrm{Me}) \mathrm{C}=)\right]_{2}$ and 1.702 (4) $\AA$ for [Ti(TMEDA $\left.)(\mathrm{Cl})_{2}(\mathrm{NPh})\right]^{37} \mathrm{Zr}$-imido bond lengths of 1.826 (4) ${ }^{38 \mathrm{a}}$ and $1.873(7) \AA^{38 \mathrm{~b}}$ are reported for $\mathrm{Cp}_{2} \mathrm{Zr}\left(\mathrm{NCMe}_{3}\right)$ (THF) and $\mathrm{Cp}_{2} \mathrm{Zr}\left(\mathrm{NNPh}_{2}\right)\left(p-\mathrm{NMe}_{2}(\mathrm{py})\right)$, respectively. ${ }^{39}$ The $\mathrm{Zr}$-imido bond length for $\mathrm{Zr}(\mathrm{NHAr})_{2}\left(\mathrm{py}^{\prime}\right)_{2}$ (NAr) is 1.868 (3) $\AA^{.13}$

Since structurally characterized group IVB imido complexes contain neutral donor ligands, the following question arises: how much does their coordination affect the MN bond? To address this question, geometry optimizations were done on $\mathrm{H}_{2}\left(\mathrm{H}_{2} \mathrm{O}\right) \mathrm{M}$ (NR), $M=\mathrm{Ti}, \mathrm{Zr}, 12$. Apart from the expected change to tetrahedral geometry, only minor perturbations are effected by coordination of water. The $\mathrm{MN}$ bond lengthens by $\approx 0.02 \AA$.

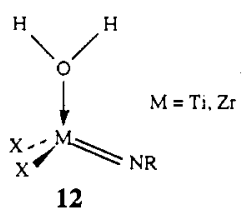

To assess the significance of electron correlation, MCSCF geometry optimizations were carried out on $\mathrm{H}_{2} \mathrm{M}(\mathrm{NH})$ at the $C_{2 v}$ $(\mathrm{M}=\mathrm{Ti})$ and $C_{s}(\mathrm{M}=\mathrm{Zr}$ or $\mathrm{Hf})$ minima. As expected, $\mathrm{MN}$ bonds lengthen slightly, $0.04 \AA(\mathrm{Ti}), 0.03 \AA(\mathrm{Zr})$, and $0.03 \AA(\mathrm{Hf})$, compared to RHF minima. The Hartree-Fock (HF) configuration $\left(\sigma^{2} \pi_{\|}^{2} \pi_{\perp}^{2} \pi_{\perp}^{* 0} \pi_{\|}^{* 0} \sigma * 0\right)$ makes a $90 \%$ contribution to the MCSCF wave function for $\mathrm{Ti}$ and $93 \%$ for the heavier congeners. As a comparison, an organic analogue of these complexes, $\mathrm{H}_{2} \mathrm{C}$ $\mathrm{NH}$, has only a slightly higher (95\%) contribution from its HF configuration using the SBKJ scheme for $\mathrm{C}$ and $\mathrm{N},-31 \mathrm{G}$ for $\mathrm{H}$, and a $(6 / 6)$ FORS-MCSCF. ${ }^{40}$ The data indicate that a single-determinant wave function is a good approximation for these complexes.

c. The V Triad. Group VB imido models are pseudotetrahedral, $X_{3} M(N R), 13$. Calculated RHF minima are described in Table III. Five structures of four-coordinate V(V) imido complexes are reported by Nugent and Mayer, ${ }^{5}$ with VN bond lengths from 1.59 (1) to 1.628 (3) $\AA$. Calculated VN bond lengths are in the

(35) Hill, J. E.; Profilet, R. D.; Fanwick, P. E.; Rothwell, I. P. Angew. Chem., Int. Ed. Engl. 1990, 29, 664.

(36) (a) Roesky, H. W.; Voelker, H.; Witt, M.; Noltemeyer, M. Angew. Chem., Int. Ed. Engl. 1989, 29, 669. (b) Roesky, H. W.; Raubold, T.; Witt, M.; Bohra, R.; Noltemeyer, M. Chem. Ber. 1991, 124, 1521.

(37) Duchateau, R.; Williams, A. J.; Gambarotta, S.; Chaing, M. Y. Inorg. Chem. 1991, 30, 4863 .

(38) (a) Walsh, P. J.; Hollander, F. J.; Bergman, R. G. J. Am. Chem. Soc. 1988, 110, 8729. (b) Walsh, P. J.; Carney, M. J.; Bergman, R. G. J. Am. Chem. Soc. 1991, 113, 6343.

(39) Optimization of $\mathrm{C}_{2} \mathrm{Zr}(\mathrm{NH}), 11$, in a $C_{2 v}$ geometry yields a $\mathrm{Zr}-\mathrm{N}$ bond length of $1.83 \AA$.

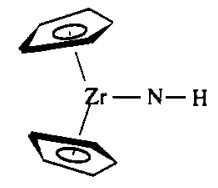

11

(40) In the RHF scheme the Hartree-Fock (HF) configuration is the only configuration and thus accounts for $100 \%$ of the wave function. As the $\mathrm{HF}$ weight approaches $100 \%$ one can usually have more confidence in a singledeterminant description.
Table III. Geometries of V Triad Imido Complexes, $\mathbf{X}_{3} \mathbf{M N R}^{a}$

\begin{tabular}{llll}
\hline & $\mathrm{V}$ & $\mathrm{Nb}$ & $\mathrm{Ta}$ \\
\hline $\mathrm{X}=\mathrm{H}, \mathrm{R}=\mathrm{H}$ & & & \\
$\mathrm{M}-\mathrm{N}$ & 1.58 & 1.72 & 1.73 \\
$\mathrm{~N}-\mathrm{R}$ & 1.01 & 1.01 & 1.01 \\
$\nu_{\mathrm{MN}}$ & 1206 & 1120 & 1124 \\
$\mathrm{X}=\mathrm{H}, \mathrm{R}=\mathrm{Cl}$ & & & \\
$\mathrm{M}-\mathrm{N}$ & 1.60 & 1.73 & 1.74 \\
$\mathrm{~N}-\mathrm{R}$ & 1.64 & 1.65 & 1.65 \\
$\nu_{\mathrm{MN}}$ & 1155 & 1072 & 1082 \\
$\mathrm{X}=\mathrm{Cl}, \mathrm{R}=\mathrm{H}$ & & & \\
$\mathrm{M}-\mathrm{N}$ & 1.56 & 1.71 & 1.72 \\
$\mathrm{~N}-\mathrm{R}$ & 1.02 & 1.02 & 1.01 \\
$\nu_{\mathrm{MN}}$ & 1255 & 1149 & 1152 \\
$\mathrm{X}=\mathrm{Cl}, \mathrm{R}=\mathrm{Cl}$ & & & \\
$\mathrm{M}-\mathrm{N}$ & 1.57 & 1.72 & 1.73 \\
$\mathrm{~N}-\mathrm{R}$ & 1.62 & 1.64 & 1.64 \\
$\nu_{\mathrm{MN}}$ & 1189 & 1097 & 1109 \\
$\mathrm{X}=\mathrm{H}, \mathrm{R}=\mathrm{Me}$ & & & \\
$\mathrm{M}-\mathrm{N}$ & 1.58 & 1.72 & 1.73 \\
$\mathrm{~N}-\mathrm{C}$ & 1.44 & 1.44 & 1.44 \\
$\nu_{\mathrm{MN}}$ & 1188 & 1105 & 1111 \\
$\mathrm{X}=\mathrm{H}, \mathrm{R}=\mathrm{SiH}$ & & & \\
$\mathrm{M}-\mathrm{N}$ & 1.58 & 1.73 & 1.74 \\
$\mathrm{~N}-\mathrm{Si}$ & 1.76 & 1.75 & 1.74 \\
$\nu_{\mathrm{MN}}$ & 1167 & 1080 & 1083 \\
\hline
\end{tabular}

${ }^{\circ}$ The values in Table III (bond lengths in $\AA$ ) were calculated with an RHF wave function and the basis sets and methods described in Computational Methods. All complexes are minima. ${ }^{b}$ Intrinsic stretching frequencies $\left(\nu_{\mathrm{MN}}\right)$, in $\mathrm{cm}^{-1}$, were calculated as described in ref 27 .

range 1.56-1.60 $\AA$, Table III. Three crystal structures are reported $^{5}$ for the tetrahedral $\mathrm{Ta}(\mathrm{V})$ species with $\mathrm{TaN}=1.763(6)$, 1.77 (2), and $1.776(8) \AA$. Calculated $\mathrm{Ta}-\mathrm{N}$ bond lengths are in the range 1.72-1.74 $\AA$, Table III. Calculated $\mathrm{NbN}$ and $\mathrm{TaN}$ bond lengths are nearly identical, Table III.

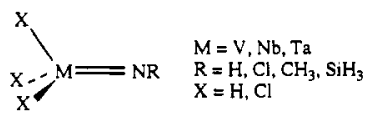

13

Two model $\mathrm{d}^{1} \mathrm{~V}(\mathrm{IV})$ imido complexes $\left(C_{2 v}\right)$ are ROHF (restricted open-shell Hartree-Fock) optimized: $\mathrm{H}_{2} \mathrm{~V}(\mathrm{NH})$ and $\mathrm{Cl}_{2} \mathrm{~V}(\mathrm{NH})$. The $\mathrm{VN}$ bond lengths are $1.61 \AA$ for $\mathrm{H}_{2} \mathrm{~V}(\mathrm{NH})$ and $1.60 \AA$ for $\mathrm{Cl}_{2} \mathrm{~V}(\mathrm{NH})$, slightly longer $(\approx 0.03 \AA)$ than the $\mathrm{V}(\mathrm{V})$ analogues. Experimentally, $V(I V)$ imidos have longer $V N$ bonds than their tetrahedral $V(V)$ counterparts: 1.665 (10) $\AA$ in $\left.\mathrm{Cp}_{2} \mathrm{~V}(\mathrm{NSiMe})_{3}\right)^{41} 1.730(5) \AA$ in $\mathrm{Cp}^{*}{ }_{2} \mathrm{~V}(\mathrm{NPh}),{ }^{42}$ and $1.707(6)$ $\AA$ in $\mathrm{CP}{ }_{2} \mathrm{~V}$ (NAr). ${ }^{14}$ Calculated VN bond lengths in the models are significantly shorter than in the $\mathrm{Cp}^{*}$ complexes but closer to the $\mathrm{Cp}$ complex. Whether these differences are due to steric or electronic factors or increasing importance of electron correlation is unclear. ${ }^{43}$

MCSCF optimizations were done on $C_{3 v} \mathrm{H}_{3} \mathrm{M}(\mathrm{NH})(\mathrm{M}=\mathrm{V}$, $\mathrm{Nb}$, or $\mathrm{Ta})$. The $\mathrm{MN}$ bond lengths are $1.63(\mathrm{~V})$ and $1.76 \AA(\mathrm{Nb}$ and $\mathrm{Ta}$ ), $\approx 3 \%$ greater than RHF. The HF configurations contribute $89 \%(\mathrm{~V}), 91 \%(\mathrm{Nb})$, and $92 \%(\mathrm{Ta})$. When comparing $\mathrm{H}_{n} \mathrm{MNH}$ results ( $n=2$ for the Ti triad, $n=3$ for the $\mathrm{V}$ triad), the Ti triad imidos are slightly better described at the HF level than their counterparts in the V triad in the same row. Although further middle and late first row TMI complexes are reported here, caution must be exercised in analyzing RHF results with these metals. However, the important conclusion is that for the coordinatively saturated complexes studied so far, the RHF description is acceptable.

(41) Wiberg, N.; Häring, H. W.; Schubert, U. Z. Naturforsch. 1980, 35B,

(42) Veith, M. Angew. Chem., Int. Ed. Engl. 1976, 15, 387.

(43) A $(7 / 7)$ FORS-MCSCF calculation at the RHF minimum energy geometry for $\mathrm{VH}_{2}(\mathrm{NH})$, i.e., the standard $(6 / 6)$ active space with the unpaired electron and orbital added, shows the Hartree-Fock (HF) configuration to account for $86 \%$ of the total FORS-MCSCF wave function, $3 \%$ less than the $\mathrm{HF}$ contribution makes to $\mathrm{VH}_{3}(\mathrm{NH})$. 
Table IV. Geometries of Cr Triad, M(NH)(E)(Cl) ${ }_{2}$ Complexes $^{a}$

\begin{tabular}{llll}
\hline & $\mathrm{Cr}$ & $\mathrm{Mo}$ & $\mathrm{W}$ \\
\hline $\mathrm{E}=\mathrm{CH}_{2}$ & & & \\
$\mathrm{M}-\mathrm{N}$ & 1.57 & 1.68 & 1.69 \\
$\mathrm{M}-\mathrm{N}-\mathrm{H}$ & 171 & 178 & 179 \\
$\mathrm{M}-\mathrm{E}$ & 2.04 & 1.89 & 1.89 \\
$\mathrm{E}-\mathrm{M}-\mathrm{N}$ & 101 & 100 & 101 \\
$\mathrm{M}-\mathrm{Cl}$ & 2.25 & 2.35 & 2.34 \\
$\mathrm{Cl}-\mathrm{M}-\mathrm{Cl}$ & 116 & 115 & 113 \\
$\nu_{\mathrm{MN}}{ }^{6}$ & 1218 & 1164 & 1181 \\
$\boldsymbol{\nu}_{\mathrm{ME}}$ & 530 & 801 & 884 \\
$\mathrm{~N} \mathrm{NH}$ & & & \\
$\mathrm{M}-\mathrm{N}$ & 1.57 & 1.70 & 1.71 \\
$\mathrm{M}-\mathrm{N}-\mathrm{H}$ & 146 & 151 & 155 \\
$\mathrm{M}-\mathrm{E}$ & 1.57 & 1.70 & 1.71 \\
$\mathrm{E}-\mathrm{M}-\mathrm{N}$ & 107 & 108 & 110 \\
$\mathrm{M}-\mathrm{Cl}$ & 2.18 & 2.33 & 2.33 \\
$\mathrm{Cl}-\mathrm{M}-\mathrm{Cl}$ & 115 & 116 & 115 \\
$\boldsymbol{\nu}_{\mathrm{MN}}$ & 787 & 1102 & 1127 \\
$\nu_{\mathrm{ME}}$ & 787 & 1102 & 1127 \\
$=\mathrm{O}$ & & & \\
$\mathrm{M}-\mathrm{N}$ & 1.97 & 1.71 & 1.72 \\
$\mathrm{M}-\mathrm{N}-\mathrm{H}$ & 117 & 137 & 146 \\
$\mathrm{M}-\mathrm{E}$ & 1.50 & 1.64 & 1.66 \\
$\mathrm{E}-\mathrm{M}-\mathrm{N}$ & 106 & 107 & 108 \\
$\mathrm{M}-\mathrm{Cl}$ & 2.22 & 2.31 & 2.31 \\
$\mathrm{Cl}-\mathrm{M}-\mathrm{Cl}$ & 122 & 113 & 114 \\
$\boldsymbol{\nu}_{\mathrm{MN}}$ & 446 & 1049 & 1145 \\
$\boldsymbol{\nu}_{\mathrm{ME}}$ & 1290 & 1150 & 1107 \\
\hline
\end{tabular}

${ }^{a}$ The geometries (bond lengths in $\AA$; bond angles in degs) for these pseudotetrahedral complexes were calculated as described in the text. The Mo and $\mathrm{W}$ complexes are minima, the $\mathrm{Cr}$ complexes each possess a single imaginary frequency, probably due in part to the poor description of the Cr-imido bond at the single-determinant level. ${ }^{b}$ The intrinsic stretching frequencies $(\nu)$, in $\mathrm{cm}^{-1}$ were calculated as described in ref 27.

d. The $\mathrm{Cr}$ Triad. The $\mathrm{Cr}$ triad complexes chosen for study are high-valent, tetrahedral complexes, 14 , with two or more multiply bonded ligands, Table IV. Based on the results for the V triad,

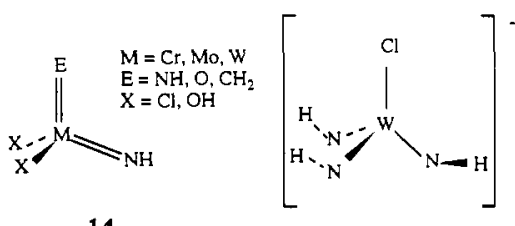

14

15

one should view uncorrelated $\mathrm{Cr}$ results with caution. However, Mo and W complexes are expected to be well-behaved based on experience with alkylidene analogues ${ }^{8,21}$ and their present behavior. For the bis(imido) Mo and $W$ complexes the calculated minima possess $C_{2 v}$ symmetry. There is often a slight asymmetry in bis(imido) complexes with one imido coordinated more linearly than the other. ${ }^{4-46}$ Searches for lower symmetry minima were unsuccessful for $\mathrm{Mo}$ and $\mathrm{W}(\mathrm{Cl})_{2}(\mathrm{NH})_{2}$. The difference between theory and experiment may arise from crystal packing forces, the nature of the ancillary ligands, or the simplicity of the model. The complex $\mathrm{Mo}(\mathrm{NAr})_{2}(\mathrm{~N}(\mathrm{H}) \mathrm{Ar}), \mathrm{Ar}=2,6-i-\mathrm{Pr}_{2}-\mathrm{Ph}$, shows distinct asymmetry. ${ }^{46}$ Calculated $\mathrm{M}-\mathrm{N}$ bond lengths for $\mathrm{Mo}(\mathrm{Cl})_{2}(\mathrm{NH})_{2}$ are $1.70 \AA$ compared with Mo-imido bond lengths of 1.723 (3) $\AA$ and 1.753 (2) $\AA$ in $\mathrm{Mo}(\mathrm{NAr})_{2}(\mathrm{~N}(\mathrm{H}) \mathrm{Ar})_{2},{ }^{46}$ the Mo-N-C angles are $155.7^{\circ}$ and $176.4^{\circ}$ for the "short" and "long" Mo-imido bonds, respectively and $151^{\circ}$ in the calculated $C_{2 v}$ minimum of $\mathrm{MoCl}_{2}(\mathrm{NH})_{2}$. A related bis(imido) complex shows little asymmetry:4sa $\mathrm{Mo}(\text { mesityl })_{2}(\mathrm{~N}-t-\mathrm{Bu})_{2} \mathrm{Mo}-\mathrm{N}=1.71 \AA, \mathrm{Mo}-\mathrm{N}^{\prime}=1.73$ $\AA, M o-N-C=160^{\circ}, M o-N^{\prime}-C^{\prime}=161^{\circ}$ as does $W(N-t-B u)_{2}-$

(44) Hursthouse, M. B.; Motevalli, M.; Sullivan, A. C.; Wilkinson, G. J. Chem. Soc., Chem. Commun. 1986, 1398. Leung, W. H.; Danopolous, A. D.; Wilkinson, G.; Hussain-Bates, B.; Hursthouse, M. B. J. Chem. Soc., Dalton Trans. 1991, 2051.

(45) Sullivan, A. C.; Wilkinson, G.; Motevalli, M.; Hursthouse, M. B. J. Chem. Soc., Dalton Trans. 1988, 53.

(46) Bryson, N.; Youinou, M. T.; Osborn, J. A. Organometallics 1991, 10, 3389.
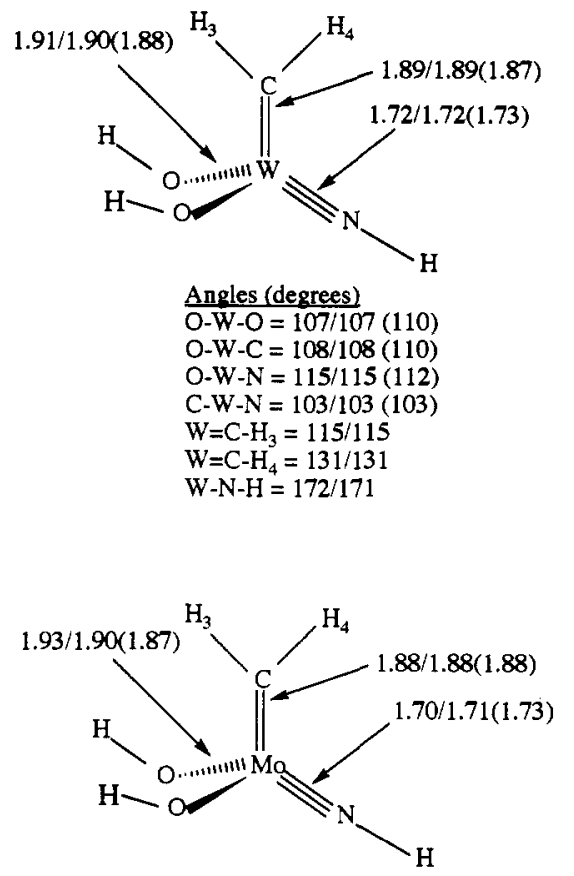

Angles (degrees)

O-Mo-O $=109 / 108(107)$

O-Mo-C $=107 / 107(109)$

O-Mo-N $=115 / 116(115)$

$\mathrm{C}-\mathrm{Mo}-\mathrm{N}=101102(100)$

$\mathrm{Mo}=\mathrm{C}-\mathrm{H}_{3}=116 / 115$

$\mathrm{Mo}=\mathrm{C} \cdot \mathrm{H}_{4}=120 / 130$

$\mathrm{M}-\mathrm{N}-\mathrm{H}=17 \mathrm{~L} / 170$

Figure 2. Comparison of calculated and experimental bond lengths and bond angles for the Mo and W Lewis acid-free olefin metathesis catalyst models. The values are quoted as previous/present (exptl), where the previous values are from ref 8 , and the experimental data comes from refs 27 and 48 . The differences between the present and previously calculated values are described more fully in the text.

$\left(2,6-\mathrm{Ph}_{2}-\mathrm{Ph}\right)_{2}{ }^{47} \mathrm{~W}-\mathrm{N}=1.730$ (3) $\AA, \mathrm{W}-\mathrm{N}^{\prime}=1.743$ (3) $\AA$, $\mathrm{W}-\mathrm{N}-\mathrm{C}=166.7^{\circ}, \mathrm{W}-\mathrm{N}^{\prime}-\mathrm{C}^{\prime}=159.2^{\circ}$. Calculated values for $C_{2 v} \mathrm{~W}(\mathrm{NH})_{2}(\mathrm{Cl})_{2}$ are $\mathrm{W}-\mathrm{N}=1.71 \AA$ and $\mathrm{W}-\mathrm{N}-\mathrm{H}=155^{\circ}$.

The $\mathrm{Mo}$ and $\mathrm{W}$ alkylidene(imido) complexes- $\mathrm{M}(\mathrm{OH})_{2}$ $(\mathrm{NH})\left(\mathrm{CH}_{2}\right), C_{s}$ symmetry-are nearly identical to that calculated previously, Figure $2,8,21$ The only difference in the two sets of calculations is the replacement of the all-electron 3-21G basis for heavy, main-group elements with SBKJ ECPs and valence basis sets in the present calculations. The SBKJ valence basis set ${ }^{24}$ is double $\zeta$ for main-group elements. As noted, ${ }^{8,21}$ calculated $W$ and $\mathrm{Mo}(\mathrm{OH})_{2}(\mathrm{NH})\left(\mathrm{CH}_{2}\right)$ data are in excellent agreement with X-ray data. ${ }^{48}$ Even simpler imido(alkylidene) models, $\mathrm{M}(\mathrm{H})_{2}(\mathrm{NH})-$ $\left(\mathrm{CH}_{2}\right)$ yield pertinent geometric parameters nearly identical to those shown in Figure 2.

The biggest difference among $\mathrm{Cr}$ triad complexes is between $\mathrm{Cr}$ and its heavier congeners. Whereas $\mathrm{Mo}$ and $\mathrm{W}$ complexes are minima at pseudotetrahedral geometries, the $\mathrm{Cr}$ analogues possess imaginary frequencies at these geometries which suggest that other than tetrahedral coordination is preferred, e.g., trigonal bipyramidal with a missing axial ligand. Note the exceptionally long $\mathrm{CrN}$ bond in $\mathrm{Cr}(\mathrm{Cl})_{2}(\mathrm{NH})(\mathrm{O}), 1.97 \AA$, Table IV. If these are artifacts due to a poor RHF description of $\mathrm{Cr}$ complexes is uncertain. MCSCF calculations $(6 / 6)$ on $\mathrm{M}(\mathrm{H})_{2}(\mathrm{NH})\left(\mathrm{CH}_{2}\right)$ models at their RHF geometries yield an $82 \%$ contribution from the HF configuration for the $\mathrm{Cr}$ complex and $\approx 91 \%$ for the heavier

(47) Kerschner, J. L.; Yu, J. S.; Fanwick, P. E.; Rothwell, I. P.; Huffman, J. C. Organometallics 1989, 8, 1414.

(48) (a) Schrock, R. R.; DePue, R. T.; Feldman, J.; Yap, K. B.; Yang, D. C.; Davis, W. M.; Park, L.; DiMare, M.; Schofield, M.; Anhaus, J.; Walborsky, E.; Evitt, E.; Kruger, C.; Betz, P. Organometallics 1990, 9, 2262. (b) Schrock, R. R.: DePue, R. T.; Feldman, J.; Schaverian, C. J.; Dewan, J. C.; Liu, A. H. J. Am. Chem. Soc. 1988, 110, 1423. (c) Bazan, G. C.; Khosravi, E.; Schrock, R. R.; Feast, W. J.; Gibson, V. C.; O'Regan, M. B.; Thomas, J. K.: Davis, W. M. J. Am. Chem. Soc. 1990, 112, 8378. 

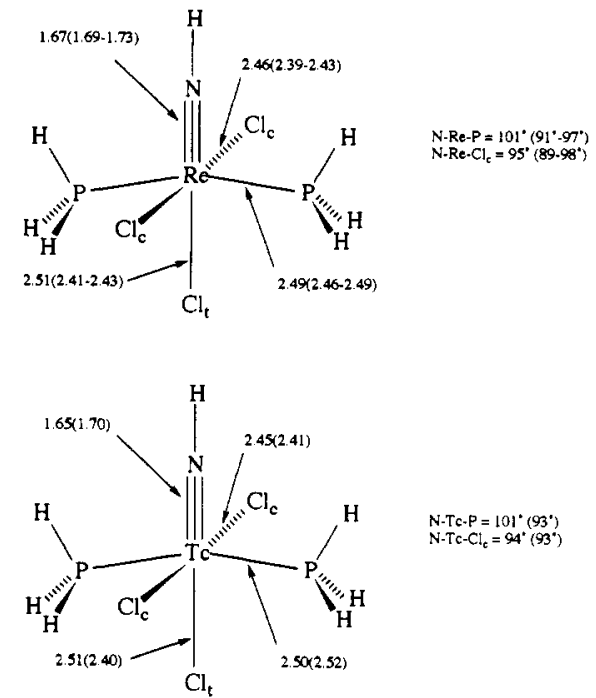

Figure 3. Comparison between calculated and experimental (in parentheses) bond lengths and angles for [trans, mer- $\left.\mathrm{Tc}\left(\mathrm{PH}_{3}\right)_{2}(\mathrm{Cl})_{3}(\mathrm{NH})\right]$ and its $R e$ analogue. The $R e$ values are taken from the three complexes characterized by Ibers and Bright; ; $3 c, d^{2}$ the experimental Tc data is averaged since the complex, [trans, mer- $\left[\mathrm{Tc}\left(\mathrm{PPh}_{3}\right)_{2}(\mathrm{Cl})_{3}(\mathrm{NPh})\right]$ is not perfectly $C_{2 v}{ }^{53 a}$ as assumed for the models.

congeners, indicating that the Mo and $\mathrm{W}$ complexes are well described at the RHF level, while a multideterminant wave function is needed to describe the $\mathrm{Cr}$-imido bond. Characterized $\mathrm{Cr}(\mathrm{NH})_{2} \mathrm{X}_{2}$ complexes ${ }^{44,45}$ possess tetrahedral geometries. Wilkinson et al. ${ }^{44,45}$ measure $\mathrm{Cr}-\mathrm{N}=1.63$ and $1.62 \AA$ and $\mathrm{Cr}-$ $\mathrm{N}-\mathrm{C}=160^{\circ}$ and $160^{\circ}$ for $\mathrm{Cr}$ (mesityl) ${ }_{2}(\mathrm{~N}-t-\mathrm{Bu})_{2}$. Schaverian et al. ${ }^{49}$ report slightly longer $\mathrm{Cr}-\mathrm{N}$ bonds $(1.64$ and $1.65 \AA$ ) for $\mathrm{Cr}(\sigma-x y l e n e d i y l)(\mathrm{N}-t-\mathrm{Bu})_{2}$ with some asymmetry in $\mathrm{Cr}-\mathrm{N}-\mathrm{C}$ angles $\left(156^{\circ}\right.$ and $\left.171^{\circ}\right)$.

Another series of complexes are the $\mathrm{W}$ tris(imido) species. ${ }^{50}$ $A C_{3}$ minimum, 15, was found for $\left[\mathrm{W}(\mathrm{NH})_{3} \mathrm{Cl}\right]^{-}: \mathrm{W}-\mathrm{N}=1.79$ $\AA, \mathrm{W}-\mathrm{Cl}=2.45 \AA, \mathrm{N}-\mathrm{W}-\mathrm{N}=112^{\circ}$, in good agreement with experiment for [W(NAr) $\left.{ }_{3} \mathrm{Cl}\right]^{-}: \mathrm{W}-\mathrm{N}=1.78 \AA$ (av), N-W-N $=113^{\circ}$ (av).$^{50}$ The calculated $\mathrm{W}-\mathrm{Cl}$ bond length is $0.11 \AA$ longer than experiment. Wigley et al.$^{50}$ state that $\mathrm{W}(\mathrm{NAr})_{3}$ would have interesting properties if made; thus, $\mathrm{W}(\mathrm{NH})_{3}$ was added to this study. W(NAr) ${ }_{3}$ analogues exist for Os and $\mathrm{Re}^{51,19}$ A $D_{3 h}$ structure, 16a, for $\mathrm{W}(\mathrm{NH})_{3}$ has two imaginary frequencies: one corresponds to bending of the WNH angles and the other to pyramidalization of the $\mathrm{W}$ coordination sphere. Movement along these modes followed by reoptimization leads to a $C_{3}$ minimum (lower than $D_{3 h}$ by $9 \mathrm{kcal} / \mathrm{mol}$ ) nearly identical to $\left[\mathrm{W}(\mathrm{NH})_{3} \mathrm{Cl}\right]^{-}$ without the chloride, $\mathrm{W}-\mathrm{N}=1.77 \AA, \mathrm{N}-\mathrm{W}-\mathrm{N}=113^{\circ}$. As will be seen, the tendency for pyramidalization is unlike characterized $\left[\mathrm{M}(\mathrm{NR})_{3}\right]^{q-}$ complexes $^{51}$ or their calculated models $\left[\mathrm{M}(\mathrm{NH})_{3}\right]^{q-}$.

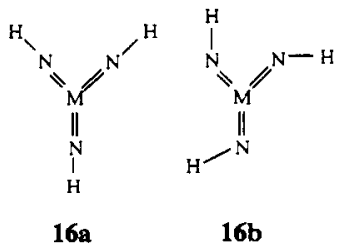

e. The Mn and Fe Triads. Experimental data for imidos from the $\mathrm{Mn}$ and $\mathrm{Fe}$ triads is primarily limited to $\mathrm{Re}$ and $\mathrm{Os}$. The imido complexes from the $\mathrm{Mn}$ and Fe triads are listed in Table V. Calculated Re-N bond lengths in $\operatorname{ReF}_{5}(\mathrm{NX})$ are 1.67 and 1.68 $\AA$ in the fluorimido and chlorimido $C_{4 v}$ minima, respectively, 0.05

(49) Meijboom, N.; Schaverian, C. J.; Orpen, A. G. Organometallics 1990 , 9,774 .

(50) Chao, Y. W.; Rodgers, P. M.; Wigley, D. E.; Alexander, S. J.; Rheingold, A. L. J. Am. Chem. Soc. 1991, I13, 6368.

(51) (a) Anhaus, J. T.; Kee, T. P.; Schofield, M. H.; Schrock, R. R. J. Am Chem. Soc. 1990, 112, 1642. (b) Williams, D. S.; Anhaus, J. T.; Schofield M. H.; Schrock, R. R.; Davis, W. M. J. Am. Chem. Soc. 1991, 113, 5480.
Table V. Geometries of $\mathrm{Mn}$ and Fe Triad Imido Complexes ${ }^{a}$

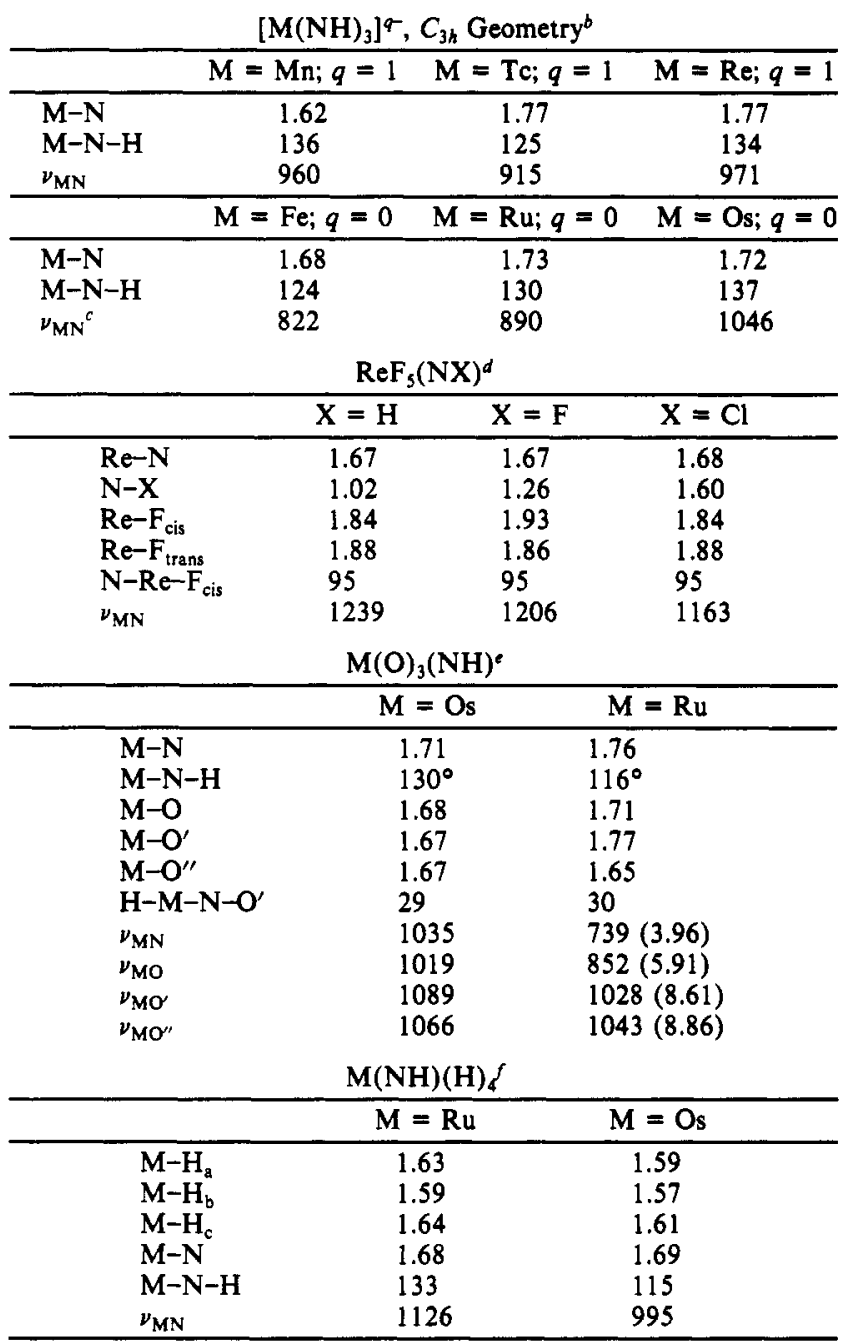

${ }^{a}$ The geometries (bond lengths in $\AA$; bond angles in deg) for these complexes were calculated at the RHF level using the basis sets and methods described in the text. ${ }^{b}$ All of the $C_{3 h}$ geometries are minima except for $\mathrm{Fe}(\mathrm{NH})_{3}$ which possesses an imaginary frequency at $75 i$ corresponding to pyramidalization of the $\mathrm{Fe}$ coordination sphere. The $D_{3 h}$ (i.e., $\mathrm{M}-\mathrm{N}-\mathrm{H}=180^{\circ}$ ) transition states are very similar (with respect to $\mathrm{M}-\mathrm{N}$ and $\mathrm{N}-\mathrm{H}$ bond lengths) to the $C_{3 h}$ minima and are not shown. 'The intrinsic stretching frequencies $(\nu)$, in $\mathrm{cm}^{-1}$, are calculated as described in ref 27. "The $C_{40}$ geometries of these pseudooctahedral complexes are all minima. "The geometries of the remaining $\mathrm{OsO}_{x}(\mathrm{NH})_{4-x}$ minima are shown in 17. The $C_{1}$ minimum of $\mathrm{Ru}(\mathrm{O})_{3-}$ $(\mathrm{NH})$ is structurally similar to that shown for the related Os complex in $17 \mathrm{a}$. $/$ See 18.

\section{$\AA$ (3\%) shorter than experiment. ${ }^{52}$}

A model of [trans,mer- $\left.\mathrm{Tc}\left(\mathrm{PPh}_{3}\right)_{2}(\mathrm{Cl})_{3}(\mathrm{NPh})\right]$ and its $\mathrm{Re}(\mathrm{V})$ analogue was studied.53 Due to their large size, the study of Tc and $\operatorname{Re}\left(\mathrm{PH}_{3}\right)_{2}(\mathrm{Cl})_{3}(\mathrm{NH})$ is limited to the highest symmetry $\left(C_{20}\right)$ rotamer. The differences in electronic structure between the $C_{2 v}$ rotamer and lower symmetry ones (e.g., those generated by $M-P$ bond rotation) are not expected to be significant, with the metal-imido bonding being primarily determined by the geometry of the $\mathrm{M}-\mathrm{N}-\mathrm{R}$ fragment and the ligand field generated by the

(52) (a) Fawcett, J.; Peacock, R. D.; Russell, D. R. J. Chem. Soc., Chem. Commun. 1982, 958. (b) Fawcell, J.; Peacock, R. D.; Russell, D. R. J. Chem. Soc., Dalton Trans. 1987, 567.

(53) (a) Nicholson, T. N.; Davison, A.; Jones, A. J. Inorg. Chim. Acto 1991, 187, 51. (b) Archer, C. M.; Dilworth, J. R.; Jobanputra, P.; Thompson, R. M.; McPartlin, M.; Povey, D. C.; Smith, G. W.; Kelly, J. D. Polyhedron 1990, 9, 1497. (c) Bright, D.; Ibers, J. A. Inorg. Chem. 1968, 7, 1099. (d) Bright, D.; Ibers, J. A. Inorg. Chem. 1969, 8, 703. (e) Forsellini, E.; Casellato, U.; Graziani, R.; Carletti, M. C.; Magon, L. Acta Crystallogr. 1984, C40, 1795 quoted in ref $5, \mathrm{p} 214$ 
remaining ligands. The calculated geometries for the $T c(V)$ and $\operatorname{Re}(V)$ complexes are shown in Figure 3 with pertinent experimental data.

For $\left[\mathrm{M}(\mathrm{NH})_{3}\right]^{q-}(\mathrm{M}=\mathrm{Mn}, \mathrm{Tc}$, or $\mathrm{Re}, q=1$; and $\mathrm{M}=\mathrm{Fe}$, $\mathrm{Ru}$, or $\mathrm{Os}, q=0)$ the $D_{3 h}$ structure, 16a, is not a minimum, but rather a related $C_{3 h}$ structure (i.e., $\mathrm{M}-\mathrm{N}-\mathrm{H}$ angles $<180^{\circ}, 16 \mathrm{~b}$, lower by only a few $\mathrm{kcal} / \mathrm{mol}$ ) is the calculated minimum, Table $\mathrm{V}$. The difference in M-N-R bending tendency between experimental ${ }^{51}$ and computational complexes may be due to the greater bulk and $\pi$-bonding effects in the substituted phenyl rings used experimentally. The OsN bond length in Os(NAr) ${ }_{3}$ is 1.74 $\AA,{ }^{51 \mathrm{a}}$ in good agreement with calculated values of $1.71 \AA$ for $D_{3 h}$ $\mathrm{Os}(\mathrm{NH})_{3}$ and $1.72 \AA$ for $C_{3 h} \mathrm{Os}(\mathrm{NH})_{3}$. Only $C_{3 h} \mathrm{Fe}(\mathrm{NH})_{3}$ is not a minimum, but has an imaginary mode corresponding to pyramidalization about the $\mathrm{Fe}$. In this respect $\mathrm{Fe}(\mathrm{NH})_{3}$ resembles $\mathrm{W}(\mathrm{NH})_{3}$, but electron correlation in $\mathrm{Mn}$ and $\mathrm{Fe}$ TMI complexes is likely to be important.

Perhaps the most well studied complexes in the $\mathrm{Mn}$ and $\mathrm{Fe}$ triads are the Os-oxo(imido) complexes: $\mathrm{Os}(\mathrm{O})_{4-x}(\mathrm{NR})_{x}{ }^{51 a, 54,55}$ Characterized examples are known for $x=1$ and $2 .{ }^{55}$ Imido and bis(imido) Os complexes have low symmetry minima as found by Nugent et al..$^{55}$ for $\mathrm{OsO}_{3}\left(\mathrm{~N}\right.$-adamantyl) and $\mathrm{OsO}_{2}(\mathrm{~N}-t-\mathrm{Bu})_{2}$. The calculated $\mathrm{Os}-\mathrm{N}-\mathrm{H}$ angle for the $C_{1}$ minimum of $\mathrm{OsO}_{3}(\mathrm{NH})$, $130^{\circ}$, is much smaller than the near linear angle $\left(171.4(4)^{\circ}\right)$ in $\mathrm{OsO}_{3}(\mathrm{~N}$-adamantyl); however, the calculated $\mathrm{Os}-\mathrm{N}$ distance in $\mathrm{OsO}_{3}(\mathrm{NH})$ of $1.71 \AA$ is in very good agreement with experiment (1.697 (4) $\AA$ ). The discrepancy in bond angles may be due to the obvious difference in size of $\mathrm{H}$ and the adamantyl group. As Nugent et al. ${ }^{55}$ show, the Os-N-C bending potential in these complexes is very soft. Replacing $\mathrm{H}$ with methyl, $\mathrm{OsO}_{3}(\mathrm{NMe})_{3}$, opens up the Os-N-C angle to slightly less than $180^{\circ}$ and thus is in improved agreement with $\mathrm{OsO}_{3}\left(\mathrm{~N}\right.$-l-adamantyl). The $C_{8}$ geometry of $\mathrm{OsO}_{2}(\mathrm{NH})_{2}$ is closest to $\mathrm{Os}(\mathrm{N}-t-\mathrm{Bu})_{2}(\mathrm{O})_{2}$ : Os-N $=1.69 \AA(\operatorname{expt}, 1.71 \AA), \mathrm{Os}^{-\mathrm{N}^{\prime}}=1.74 \AA$ (expt, $\left.1.72 \AA\right), \mathrm{Os}^{-}$ $\mathrm{N}-\mathrm{H}(\mathrm{C})=162^{\circ}\left(\operatorname{expt}, 179^{\circ}\right), \mathrm{Os}-\mathrm{N}^{\prime}-\mathrm{H}^{\prime}\left(\mathrm{C}^{\prime}\right)=123^{\circ}(\mathrm{expt}$, $\left.155^{\circ}\right)$. With all symmetry constraints lifted, optimization yields a $\mathrm{C}_{1}$ minimum, $17 \mathrm{~b}$.

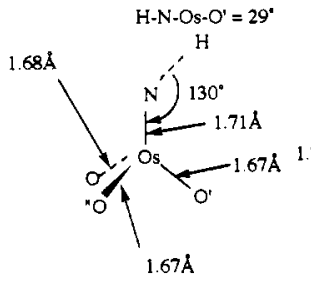

$17 \mathbf{a}-\mathrm{C}_{1}$

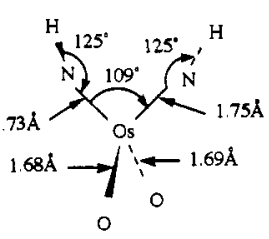

$17 \mathbf{b}-\mathrm{C}_{1}$

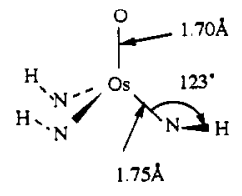

$17 \mathrm{c}-\mathrm{C}_{3}$
Shapley et al. have synthesized $\mathrm{Os}(\mathrm{NMe})\left(\mathrm{CH}_{2} \mathrm{SiMe}_{3}\right)_{4}$ and performed a crystal structure analysis. ${ }^{56} \mathrm{OsH}_{4}(\mathrm{NH}), 18$, like $\mathrm{Os}(\mathrm{NMe})\left(\mathrm{CH}_{2} \mathrm{SiMe}_{3}\right)_{4}$ is intermediate between a trigonal bipyramid and square pyramid: $O s-N=1.686$ (5) $\AA$ (1.68 $\AA$, calcd), Os-N-C $=164^{\circ}\left(133^{\circ}, \mathrm{Os}-\mathrm{N}-\mathrm{H}\right.$, calcd). $\mathrm{OsH}_{4}(\mathrm{NMe})$ was also optimized. The $\mathrm{Os}-\mathrm{N}$ bond in $\mathrm{OsH}_{4}(\mathrm{NMe})$ is slightly shorter $\left(1.67 \AA\right.$ ), and $\mathrm{Os}-\mathrm{N}-\mathrm{C}=157^{\circ}$, much closer to experiment. The improved agreement in Os- $\mathrm{N}-\mathrm{R}$ angles upon replacement of $\mathrm{H}$ with $\mathrm{Me}$ for the Os complexes is encouraging.

f. The $\mathrm{Co}, \mathrm{Ni}$, and $\mathrm{Cu}$ Triads. The hypothetical $C_{50} \mathrm{CpRhNH}$ complex $(\mathrm{Rh}-\mathrm{C}=2.27 \AA, \mathrm{Rh}-\mathrm{N}=1.71 \AA)$ has a doubly degenerate imaginary mode at $190 i$ indicating that bending of the $\mathrm{M}-\mathrm{N}-\mathrm{H}$ bond angle from $180^{\circ}$ is desired; the Co analogue is a minimum at a $C_{5 v}$ geometry $\left(C_{0}-\mathrm{C}=2.16 \AA, C_{0}-\mathrm{N}=1.58 \AA\right)$, $\mathrm{CpIrNH}$ is a minimum at the $C_{5 v}$ geometry, 8, with $\mathrm{Ir}-\mathrm{Ct}=1.92$

(54) (a) Clifford, A. F.; Kobayashi, C. S. 130th National ACS Meeting Atlantic City, Sept. 1956, paper 50R quoted in Clifford, A. F.; Kobayashi, C. S. Inorg. Synth. 1960, 6, 204. (b) Chong, A. O.; Oshima, K.; Sharpless, K. B. J. Am. Chem. Soc. 1979, 99, 3420. (c) Chong, A. O.; Oshima, K.; Sharpless, K. B. J. Org. Chem. 1976, 41, 177.

(55) Nugent, W. A.; Harlow, R. L.; McKinney, R. J. J. Am. Chem. Soc. $1979,101,7265$.

(56) (a) Shapley, P. A. B.; Own, Z. Y.; Huffman, J. C. Organometallics 1986, 5, 1269. (b) Marshman, R. W.; Shapley, P. A. J. Am. Chem. Soc. 1990 112,8369 .

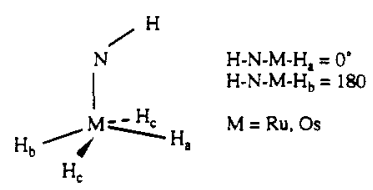

18

$\AA(\mathrm{Ir}-\mathrm{C}=2.27 \AA), \mathrm{Ir}-\mathrm{N}=1.70 \AA$, and an electronic structure in accord with that described. ${ }^{30 b}$ The experimental values for $\mathrm{Cp} * \operatorname{Ir}(\mathrm{NR})$ have $\mathrm{Ir}-\mathrm{N}$ bond lengths ranging from 1.712 (7) to 1.750 (7) $\AA .{ }^{30}$ The average $\mathrm{Ir}-\mathrm{C}$ distance in $\mathrm{Cp} \mathrm{p}^{*} \operatorname{Ir}(\mathrm{N}-t-\mathrm{Bu})$ is $\approx 2.19 \AA .30,57$

The Ni triad complexes, $\mathrm{M}\left(\mathrm{PR}_{3}\right)_{2}(\mathrm{NH})$, were optimized in a $C_{s}$ geometry, 19. The $\mathrm{P}-\mathrm{H}$ bonds are normal $(1.41 \AA)$, and $\mathrm{M}-\mathrm{P}-\mathrm{H}$ angles are approximately tetrahedral. Only the $\mathrm{Pt}$ complex is a minimum at the $C_{s}$ geometry; the $\mathrm{Pd}$ and $\mathrm{Ni}$ complexes possess imaginary frequencies corresponding to rotation about the $\mathrm{M}-\mathrm{N}$ bond and compression of one of the $\mathrm{P}-\mathrm{M}-\mathrm{N}$ angles. Distortion along these internal coordinates followed by geometry optimization leads to distorted structures corresponding to reductive elimination of phosphineimine $\left(\mathrm{H}_{3} \mathrm{PNH}\right)$. Note the small $\mathrm{M}-\mathrm{N}-\mathrm{H}$ angle for the $\mathrm{Pt}$ complex $\left(115^{\circ}\right)$; replacing the imido $\mathrm{H}$ with $\mathrm{Me}$ causes the $\mathrm{Pt}-\mathrm{N}-\mathrm{R}$ angle to expand to $133^{\circ}$, still smaller than almost all reported $\mathrm{M}-\mathrm{N}-\mathrm{R}$ angles. ${ }^{32} \mathrm{~A}$ Pt$\left(\mathrm{PR}_{3}\right)_{2}(\mathrm{NR})$ complex has been reported as a product in the reaction of $\mathrm{Pt}\left(\mathrm{PR}_{3}\right)_{4}$ with a perfluorinated azide; no crystal structure was reported and would be very interesting. ${ }^{58}$

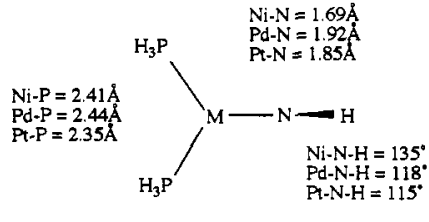

$19-C_{s}$

2. Electronic Structure of Imido Complexes. The good agreement between experimental and theoretically predicted structures in a host of geometries and oxidation states, incorporating transition metals from nearly the entire series, indicates that this choice of ECPs and valence basis sets is reliably describing the electronic structure of imido complexes.

The method chosen to analyze the electronic structure of imido complexes is the MC/LMO/CI technique described above. Briefly, $\mathrm{MC} / \mathrm{LMO} / \mathrm{CI}$ allows one to extract valence bond resonance structures from a FORS-MCSCF wave function. Being an MO-based method, MC/LMO/CI combines the computational advantages of MO theory (e.g., orthogonal determinants) with the chemical intuitiveness of valence bond theory. Note that the wave function has not been altered, but recast in a different form. Given that the electronic structure and reactivity of transition metal complexes is often phrased in valence bond terms (i.e., which resonance or Lewis structure dominates) it is hoped that this is a more meaningful form.

The two main limitations of the $\mathrm{MC} / \mathrm{LMO} / \mathrm{CI}$ method lie in the first step. Sometimes the lowest energy MCSCF wave function is that in which the correlating MO for a particular bonding orbital is not its antibonding counterpart ("left-right" correlation), but rather one with a higher principal quantum number ("in-out" correlation). For example, in $\left(\mathrm{PH}_{3}\right)_{2} \mathrm{Pt}(\mathrm{NH})$ one of the " $\pi$ components" is essentially a $\mathrm{N}$ lone pair. The correlating MO for the lone pair is also a $\mathrm{N}$ lone pair, but with a higher principal quantum number (as evidenced by a radial node). Boys localization of "in-out" correlated MOs does not yield "AO-like" MOs. The preference for "in-out" correlation is more frequent for low-valent, late transition metal complexes with highly polarized metal-ligand bonds (e.g., $\left(\mathrm{PH}_{3}\right)_{2} \mathrm{Pt}(\mathrm{NH}), \mathrm{ClCo}(\mathrm{NH})$, or $\mathrm{Zn}$ complexes). Since FORS-MCSCF is computationally intensive

(57) Hollander, F. J. Personal communication.

(58) McGlinchey, M. J.; Stone, F. G. A. J. Chem. Soc., Chem. Commun. $1970,1265$. 


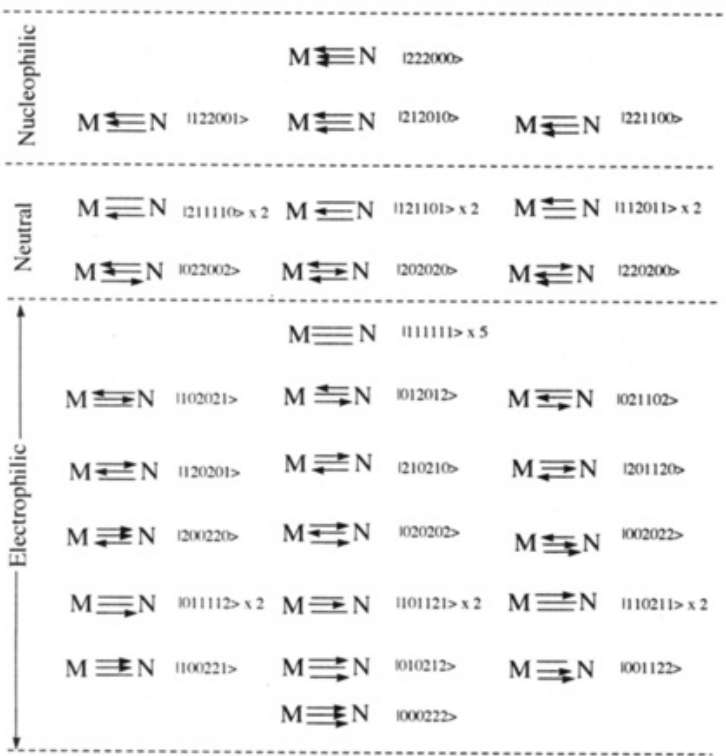

Figure 4. "Chemical" resonance contributors for a metal-nitrogen triple bond. A covalent bond is represented by a straight line, a dative bond by an arrow pointing from ligand to metal, and a back-bond by an arrow pointing from metal to ligand. Of the three components which comprise the triple bond, the bottom line (or arrow) describes the $\sigma$ component and the middle and top lines (or arrows) represent the $\pi$ components.

in terms of memory and time, one is often limited to the simplest models of known complexes, i.e., replace $\mathrm{Cl}$ and alkyl with $\mathrm{H}, \mathrm{Cp}$ with $\mathrm{Cl}$, etc. Fortunately, $\mathrm{MC} / \mathrm{LMO} / \mathrm{CI}$ has not proven to be overly sensitive to computational (basis set, localization method, etc.) and chemical (ligand and substituent modification, within reason) details. ${ }^{8,22}$

A triple bond is described by 175 resonance structures. However, chemical intuition leads one to expect that Lewis structures with three two-center/two-electron bonds will be dominant. Configurations can be denoted $\mid\{\sigma(\mathrm{N})\}^{i}\left\{\pi_{\perp}(\mathrm{N})\right\}^{4}\left\{\pi_{\perp}(\mathrm{N})\right\}^{k}\left\{\pi_{\perp}\right.$ $\left.(\mathrm{M})\}^{l}\left(\pi_{\|}(\mathrm{M})\right\}^{m}\{\sigma(\mathrm{M})\}^{n}\right\rangle$ or $|i j k l m n\rangle$ using shorthand notation where $i, j, k, l, m$, and $n$ are the occupation numbers of the "AO-like" MOs). A "chemical" resonance structure would have $i+n=j$ $+m=k+l=2$. There are 37 configurations (spatial and spin) which satisfy the "chemical" criterion for all three bonding components, and only 27 spatial configurations, Figure 4 . It is satisfying that the $\mathrm{MC} / \mathrm{LMO} / \mathrm{CI}$ method shows that "chemical" resonance structures comprise the dominant $(\approx 99 \%)$ portion of the resonance contributors. Different configurations can have the same spatial component, since there are two ways to singlet couple four electrons in four orbitals (i.e., $\alpha \alpha \beta \beta$ and $\alpha \beta \alpha \beta$ ) and five ways to singlet couple six electrons in six orbitals $(\alpha \alpha \alpha \beta \beta \beta, \alpha \alpha \beta \beta \alpha \beta$, $\alpha \beta \alpha \alpha \beta \beta, \alpha \alpha \beta \alpha \beta \beta$, and $\alpha \beta \alpha \beta \alpha \beta)$. Contributions from configurations with the same spatial part are combined in the MC/ $\mathrm{LMO} / \mathrm{CI}$ analysis. The standard notation in depicting and describing resonance structures has been employed in Figure 4. A line represents a covalent bond, while a dative bond is signified by an arrow pointing from ligand to metal, and a back-bond is depicted by an arrow pointing from the metal to ligand. The bottom arrow (or line) describes the metal-imido $\sigma$ bond while the top and middle arrow (or line) represent the $\pi$ components which are perpendicular and parallel, respectively, to the $\mathrm{M}-\mathrm{N}-\mathrm{R}$ plane, 5.

Another simplification is to treat both $\pi$ components ( $\pi_{1}$ and $\left.\pi_{\perp}, 5\right)$ as equal so that those configurations which differ by having the occupation numbers for the $\pi$ components juxtaposed, e.g., |120201) and |102021), are summed together. Graphically, this means that resonance structures $20 \mathrm{a}$ and $20 \mathrm{~b}$ are equal. For cases such as $\mathrm{MH}_{3} \mathrm{NH}(\mathrm{M}=\mathrm{V}, \mathrm{Nb}$, or $\mathrm{Ta})$, both $\pi$ bonds are symmetry equivalent and the assumption is strictly correct; for $\mathrm{MH}_{2} \mathrm{NH}(\mathrm{M}$ $=\mathrm{Ti}, \mathrm{Zr}$, or $\mathrm{Hf}$ ), the two $\pi$ bonds (parallel and perpendicular to the molecular plane) are not equivalent. As expected, the perpendicular $\pi$ bond is more covalent, while the parallel $\pi$ bond is more lone pair like as shown schematically in 21. However, the contributions for configurations such as $|212010\rangle$ and $|221100\rangle$ are always within a few percent of each other, especially for near linear $\mathrm{M}-\mathrm{N}-\mathrm{R}$ angles.

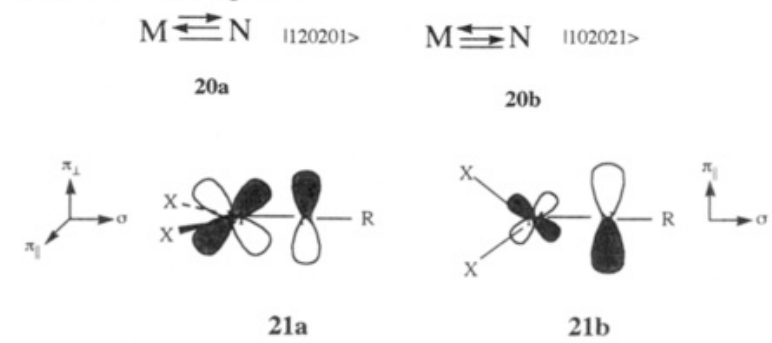

One helpful tool for analyzing $\mathrm{MC} / \mathrm{LMO} / \mathrm{CI}$ results is to classify the "chemical" resonance structures as nucleophilic, electrophilic, and neutral. Nucleophilic resonance structures are those with a formal negative charge on the imido nitrogen. For the purposes of calculating the formal charge the N-R bond is considered to be covalent and thus contributes 1 electron to the nitrogen's total. In $|i j k l m n\rangle$ notation, nucleophilic resonance structures will be those in which $i+j+k=5$ or 6 . Similarly, electrophilic resonance structures are those in which the imido nitrogen has a formal positive charge $(i+j+k \leq 3)$. When $i$ $+j+k=4$, the resonance structure is a neutral one.

The prime resonance contributors for a representative assortment of early, middle, and late transition metal imido complexes are shown in Table VI. Several interesting points concerning the nature of the transition metal-imido bond are evident from the $\mathrm{MC} / \mathrm{LMO} / \mathrm{CI}$ results, the highlights of which are collected here.

(i) Eight resonance structures account for roughly $90-95 \%$ of the contributions to the ground-state description of the metalimido bond. Only these prime prime resonance contributors are shown in Table VI. Thus, the metal-imido linkage cannot be described by one "best" Lewis structure but rather a linear combination of several is needed for an accurate description. A similar conclusion was reached for the metal-carbon double bond of alkylidene complexes, except in that case there were five prime resonance contributors. ${ }^{8}$ That a particular bond is described in terms of several resonance contributors is often not evident in descriptions derived from observed chemical reactivity or ordinary MO calculations, but is clearly demonstrated by the MC/ $\mathrm{LMO} / \mathrm{CI}$ technique.

(ii) Two of the eight prime resonance contributors correspond to bonding descriptions not previously considered in the literature: $|211110\rangle$ ( $\sigma$-ylide), 22, comprise a dative $\sigma$ and two covalent $\pi$ bonds and $|212010\rangle$ and $|221100\rangle(\sigma, \pi$-ylide $), 23$, formed from a dative $\sigma$ and a dative $\pi$ bond plus one covalent $\pi$ bond. The $\sigma$-ylide and $\sigma, \pi$-ylide account for roughly $40 \%$ of the ground-state description of the metal-imido bond and are two of the three largest resonance contributors. The third big contributor is the polarized triple bond description discussed above, 3. As found for alkylidene complexes, there is a significant dative character in the metal-ligand $\sigma$ bond. ${ }^{8}$

$$
\mathrm{M} \rightleftharpoons \mathrm{N} 1211110>\quad \mathrm{M} \leftleftarrows \mathrm{N} \quad \underbrace{1212010>\quad \mathrm{M}}_{23} \underbrace{1221100>}
$$

(iii) The other five prime resonance structures contribute approximately $5-10 \%$ each depending on the TMI complex: allcovalent (1), 6-electron donor (7), Basolo's imide (6) and nitrene descriptions (20), and singlet nitrene (24), Table VI. Each of these bonding models has been invoked to describe the metal-imido bond of various TMI complexes. $3,5,20,31,58$ Rather than any of these being the "best" description of the metal-imido bond, the MC/LMO/CI method shows each to be small, but important, contributors.

$$
\mathrm{M} \rightleftarrows \mathrm{N} \quad \underset{24}{1202020>} \quad \mathrm{M} \rightleftarrows \mathrm{N} \quad 1220200>
$$

(iv) The singlet nitrene description, similar to that suggested by Stone et al. for late TMI complexes, ${ }^{58}$ remains roughly the same $(\approx 5-6 \%)$ regardless of the complex. It is unfortunate that the 

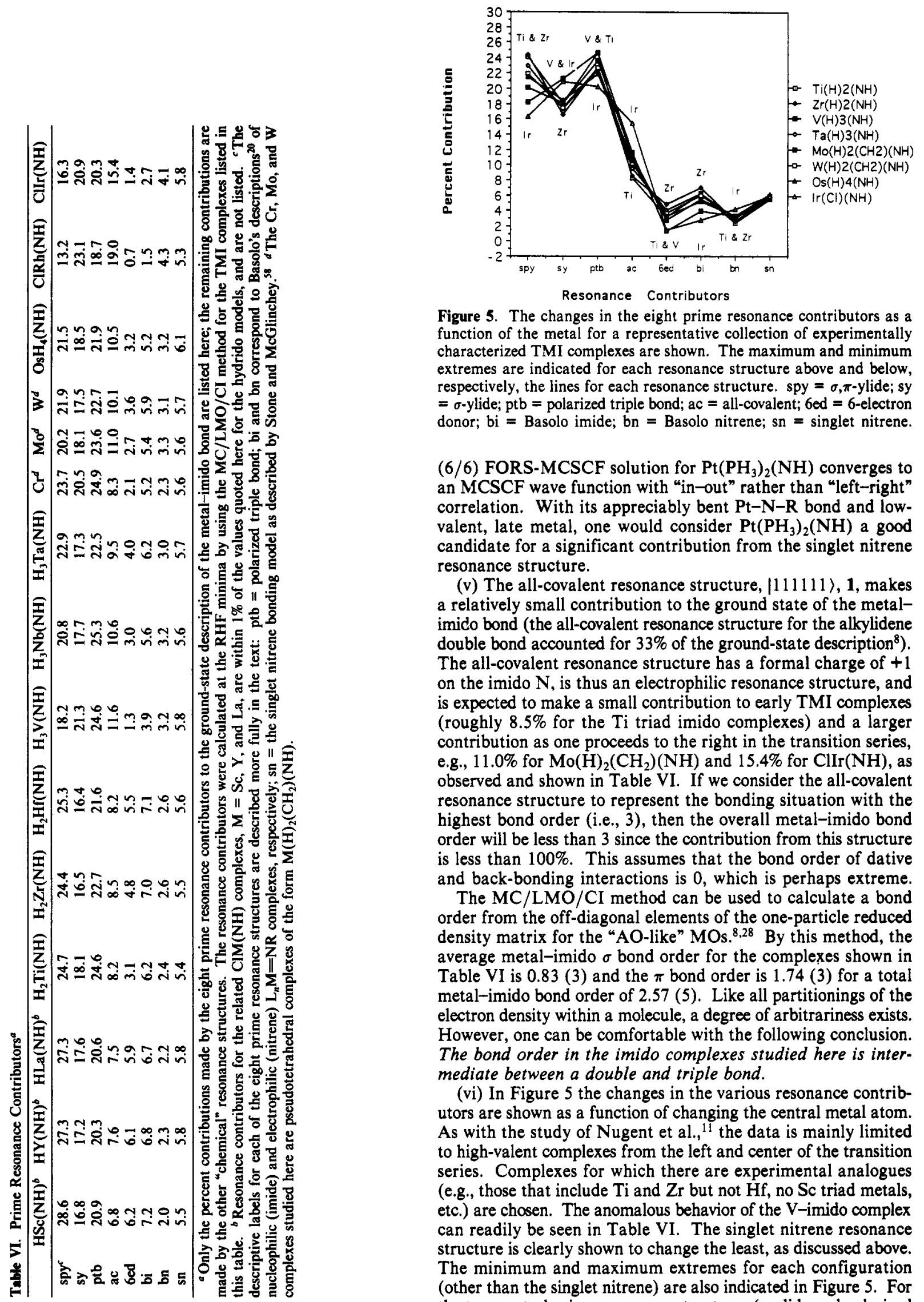

Figure 5. The changes in the eight prime resonance contributors as a function of the metal for a representative collection of experimentally characterized TMI complexes are shown. The maximum and minimum extremes are indicated for each resonance structure above and below, respectively, the lines for each resonance structure. spy $=\sigma, \pi$-ylide; sy $=\sigma$-ylide; $\mathrm{ptb}=$ polarized triple bond; $\mathrm{ac}=$ all-covalent; $6 \mathrm{ed}=6$-electron donor; $\mathrm{bi}=$ Basolo imide; $\mathrm{bn}=$ Basolo nitrene; $\mathrm{sn}=$ singlet nitrene.

(6/6) FORS-MCSCF solution for $\operatorname{Pt}\left(\mathrm{PH}_{3}\right)_{2}(\mathrm{NH})$ converges to an MCSCF wave function with "in-out" rather than "left-right" correlation. With its appreciably bent $\mathrm{Pt}-\mathrm{N}-\mathrm{R}$ bond and lowvalent, late metal, one would consider $\operatorname{Pt}\left(\mathrm{PH}_{3}\right)_{2}(\mathrm{NH})$ a good candidate for a significant contribution from the singlet nitrene resonance structure.

(v) The all-covalent resonance structure, $|111111\rangle, 1$, makes a relatively small contribution to the ground state of the metalimido bond (the all-covalent resonance structure for the alkylidene double bond accounted for $33 \%$ of the ground-state description $\left.{ }^{8}\right)$. The all-covalent resonance structure has a formal charge of +1 on the imido N, is thus an electrophilic resonance structure, and is expected to make a small contribution to early TMI complexes (roughly $8.5 \%$ for the $\mathrm{Ti}$ triad imido complexes) and a larger contribution as one proceeds to the right in the transition series, e.g., $11.0 \%$ for $\mathrm{Mo}(\mathrm{H})_{2}\left(\mathrm{CH}_{2}\right)(\mathrm{NH})$ and $15.4 \%$ for $\mathrm{ClIr}(\mathrm{NH})$, as observed and shown in Table VI. If we consider the all-covalent resonance structure to represent the bonding situation with the highest bond order (i.e., 3), then the overall metal-imido bond order will be less than 3 since the contribution from this structure is less than $100 \%$. This assumes that the bond order of dative and back-bonding interactions is 0 , which is perhaps extreme.

The MC/LMO/CI method can be used to calculate a bond order from the off-diagonal elements of the one-particle reduced density matrix for the "AO-like" MOs. ${ }^{8,28}$ By this method, the average metal-imido $\sigma$ bond order for the complexes shown in Table VI is 0.83 (3) and the $\pi$ bond order is 1.74 (3) for a total metal-imido bond order of 2.57 (5). Like all partitionings of the electron density within a molecule, a degree of arbitrariness exists. However, one can be comfortable with the following conclusion. The bond order in the imido complexes studied here is intermediate between a double and triple bond.

(vi) In Figure 5 the changes in the various resonance contributors are shown as a function of changing the central metal atom. As with the study of Nugent et al. ${ }^{11}$ the data is mainly limited to high-valent complexes from the left and center of the transition series. Complexes for which there are experimental analogues (e.g., those that include $\mathrm{Ti}$ and $\mathrm{Zr}$ but not $\mathrm{Hf}$, no Sc triad metals, etc.) are chosen. The anomalous behavior of the V-imido complex can readily be seen in Table VI. The singlet nitrene resonance structure is clearly shown to change the least, as discussed above. The minimum and maximum extremes for each configuration (other than the singlet nitrene) are also indicated in Figure 5. For the two neutral prime resonance structures $(\sigma$-ylide and polarized triple bond), different behavior is exhibited. The $\sigma$-ylide, with its dative $\sigma$-bond, increases from left to right in the transition series while the polarized triple bond resonance structure decreases from left to right. Nucleophilic resonance structures (the $\sigma, \pi$-ylide, Basolo's imide, and the six-electron donor) are largest for the early 
metals and decrease as one proceeds to the left. Electrophilic resonance structures (the all-covalent and Basolo's nitrene description) show the opposite trend. These changes are in agreement with observed reactivity and are a quantitative (or semiquantitative) confirmation of the concepts first suggested by Nugent et al." The MC/LMO/CI method clearly shows changes in contributions from the various resonance structures which are in accord with, and contribute to, the changes in chemical reactivity of transition metal imido complexes.

3. Summary. In this paper ab initio molecular orbital calculations are reported for a representative portion of the many transition metal imido complexes which have been experimentally characterized. Several important points have been made, the most significant of which are summarized here.

For the majority of complexes, essentially all those in the second and third transition series plus the early part of the first series, a RHF wave function is sufficiently accurate to avoid the added computational expense of going to a multideterminant description. Of course, calibration of any theoretical model with experimental data is an important first step before embarking on a computational study of the bonding and reactivity of a new family of complexes. Perhaps more importantly, where experimental data is available, the agreement between calculated and experimental geometries ranges from very good to excellent. These results echo those from extensive studies of multiply bonded transition metal-group IVA complexes (carbenes, silylenes, etc.). ${ }^{8,21,22}$ As a whole, these results lend confidence to the assertion that as long as the molecule is described by the appropriate wave function (RHF, MCSCF, etc.) good confidence in geometric predictions can be had with the present combination of ECPs and valence basis sets. It is hoped that the present research encompassing complexes from the entire transition series (excluding only the $\mathrm{Zn}$ triad) will encourage further concentration of quantum chemical research in the transition metals and their complexes.
Eight resonance structures account for approximately $90 \%$ of the ground-state description of the metal-imido bond; three of these are most important, comprising roughly two-thirds of the total contributions. Of the three prime resonance contributors, two are novel bonding descriptions while the third is the familiar polarized triple bond description. For the two Lewis structures which have not previously entered into discussion in the literature, both possess a dative $\sigma$ bond. The $\mathrm{MC} / \mathrm{LMO} / \mathrm{CI}$ results also suggest that the correct formulation for the transition metal-imido bond is intermediate between a triple and double bond. $\mathrm{Nu}$ cleophilic resonance structures decrease as one proceeds to the right in the transition series while electrophilic resonance structures act conversely.

Acknowledgment. This research has profited greatly from interactions with Mark Gordon, Mike Schmidt, and the rest of the quantum chemistry group at Iowa State University plus the NIST (National Institutes of Standards and Technology) group: Walter Stevens, Morris Krauss, Harold Basch (present address: Bar Ilan), and Paul Jasien (present address: University of San Diego). The generous financial support of Memphis State University (through a Faculty Research Grant) and the Department of Chemistry is acknowledged as is the generosity of the Digital Equipment Corporation for the loan of a DECstation $5000 / 200$ upon which the bulk of these calculations were carried out. A grant of time on the Cray Y-MP4/464 (Grant No. CHE92007N) at the National Center for Supercomputing Applications (NCSA), funded in part by the National Science Foundation, was instrumental in carrying out several of the larger calculations reported here. Helpful suggestions by Professor Henry A. Kurtz (Memphis State) and the communication of unpublished results by Professor James F. Harrison (Michigan State University) and Dr. F. J. Hollander (CHEXRAY, Berkley) are also appreciated. 